\title{
DETENCIÓN, GARANTÍAS ESENCIALES Y ESTADO DE DERECHO EN LA JURISPRUDENCIA DEL TEDH
}

ANA SALINAS DE FRÍAS 
SUMARIO

1. INTRODUCCIÓN. 2. POSIBLES CAUSAS DE DETENCIÓN EN RELACIÓN A LA LUCHA CONTRA EL TERRORISMO. 3. CONDICIONES DE LA DETENCIÓN EN LOS CASOS DE TERRORISMO. 4. ASILO, DEVOLUCIÓN Y EXPULSIÓN EN SUPUESTOS DE TERRORISMO. 5. TERRORISMO Y EXTRADICIÓN A LOS EFECTOS DE EXTRADICIÓN. 6. LA PROHIBICIÓN ABSOLUTA DE LA TORTURA O DE TRATOS O PENAS CRUELES, INHUMANOS O DEGRADANTES COMO PRINCIPIO GENERAL DE BASE DE TODA PRIVACIÓN DE LIBERTAD. 7. ALGUNAS CONCLUSIONES FINALES. 


\title{
DETENCIÓN, GARANTÍAS ESENCIALES Y ESTADO DE DERECHO EN LA JURISPRUDENCIA DEL TEDH
}

\author{
POR \\ ANA SALINAS DE FRÍAS \\ Profesora Titular de Derecho Internacional Público y Relaciones \\ Internacionales, Universidad de Málaga*
}

\section{INTRODUCCIÓN}

Entre los derechos fundamentales lesionados como consecuencia de la «guerra» contra el terrorismo, el derecho a la libertad y seguridad personal es sin duda uno de los más directa y profundamente afectados. En realidad no se trata sólo de la desprotección de los derechos más elementales de la persona, sino también del rampante desmantelamiento del Estado de Derecho.

Esto ha ocurrido no sólo en los Estados Unidos de América, sino que Europa se ha visto seriamente afectada, con episodios de detenciones arbitrarias, torturas, entregas extraordinarias, supresión del habeas corpus y, por derivación, la desaparición del derecho a un juicio justo con todas las garantías procesales o del principio de legalidad. Si en Estados Unidos la respuesta ha levantado grandes heridas por su tradición democrática de más de 200 años, en Europa ha sido

* Asesora jurídica de la Dirección de Asuntos Jurídicos y Derecho Internacional Público del Consejo de Europa. Las opiniones vertidas en el presente artículo lo son a título individual y no comprometen a la organización internacional en cuestión. 
triste descubrir como las voces sesgadas de los gobiernos y sus respuestas «securitarias» han presionado contra el patrimonio jurídico atesorado por el Estado de Derecho.

Anclado en una férrea convicción democrática, que le ha permitido soportar la tentación del momento, la presión social que la barbarie terrorista sin duda provoca, y la resistencia de los Estados, el TEDH ha contribuido y contribuye de manera esencial a ese patrimonio jurídico.

El principal objetivo de este estudio es, pues, redescubrir que existe un sistema de lucha eficaz contra el terrorismo, provisto de todas las garantías necesarias, el del TEDH, y que sigue evolucionando para dar respuestas adecuadas a las nuevas expresiones de esta lacra internacional. En este sentido se podría decir que no se justifican las espurias argumentaciones para abandonar el sistema so pretexto de situaciones de emergencia o de estados de excepción, o para la concesión ilimitada de poderes extraordinarios al ejecutivo y, por el contrario, que las iniciativas jurídicas basadas en el respeto de los derechos fundamentales constituyen la única respuesta eficaz contra el terrorismo.

Los ya más de cincuenta años de ejercicio jurisdiccional por parte del TEDH nos ofrecen más de un centenar de casos en los que se ha dilucidado la compatibilidad de las técnicas, políticas y estrategias nacionales de lucha contra el terrorismo con la debida protección de los derechos fundamentales recogidos en el CEDH, en especial en lo que atañe a los derechos a la vida, a la libertad y a la seguridad, a un juicio justo y la prohibición de la tortura.

La extensa jurisprudencia del Tribunal ha aportado, pues, unas pautas insustituibles a la hora de compatibilizar la lucha contra el terrorismo internacional por parte de los Estados miembros del Consejo de Europa con el respeto de los derechos humanos y el Estado de Derecho, al tiempo que ha contribuido a perfeccionar la cooperación internacional entre los Estados en la lucha contra el terrorismo. Es en estos aspectos - que constituyen, por otra parte, el grueso de la jurisprudencia del Tribunal en materia de terrorismo internacional- en los que se adentra la presente contribución, en especial en la consideración de la jurisprudencia del TEDH en relación con el artículo 5 del CEDH, por el que se protege el derecho a la libertad y la seguridad como uno de los pilares básicos del Estado de Derecho, sin perjuicio de consideraciones adicionales que puedan ser necesarias respecto de otras disposiciones del Convenio y sus respectivas interpretaciones jurisprudenciales. 


\section{POSIBLES CAUSAS DE DETENCIÓN EN RELACIÓN A LA LUCHA CONTRA EL TERRORISMO}

El artículo 5 del $\mathrm{CEDH}^{1}$ consagra el derecho a la libertad y a la seguridad de toda persona sujeta a la jurisdicción de un Estado miembro del Consejo de Europa o, lo que es lo mismo, la prohibición general de privación de libertad. La estructura de esta disposición deja bien claro que la libertad individual es el principio de base en la protección ofrecida, mientras que las restricciones a este de-

${ }^{1}$ El texto del artículo 5 del CEDH reza del siguiente tenor:

«1. Toda persona tiene derecho a la libertad y a la seguridad. Nadie puede ser privado de su libertad, salvo en los casos siguientes y con arreglo al procedimiento establecido por la ley:

a) Si ha sido penado legalmente en virtud de una sentencia dictada por un tribunal competente.

b) Si ha sido detenido preventivamente o internado, conforme a derecho, por desobediencia a una orden judicial o para asegurar el cumplimiento de una organización establecida por la ley.

c) Si ha sido detenido preventivamente o internado, conforme a derecho, para hacerle comparecer ante la autoridad judicial competente, cuando existan indicios racionales de que ha cometido una infracción o cuando se estime necesario para impedirle que cometa una infracción o que huya después de haberla cometido.

d) Si se trata del internamiento de un menor en virtud de una orden legalmente acordada, con el fin de vigilar su educación o de su detención, conforme a derecho, con el fin de hacerle comparecer ante la autoridad competente.

e) Si se trata del internamiento, conforme a derecho, de una persona susceptible de propagar una enfermedad contagiosa, de un enajenado, de un alcohólico, de un toxicómano o de un vagabundo.

f) Si se trata de la detención preventiva o del internamiento, conforme a derecho, de una persona para impedir que entre ilegalmente en el territorio o contra la que esté en curso un procedimiento de expulsión o extradición.

2. Toda persona detenida preventivamente debe ser informada, en el más breve plazo y en una lengua que comprenda, de los motivos de su detención y de cualquier acusación formulada contra ella.

3. Toda persona detenida preventivamente o internada en las condiciones previstas en el párrafo 1, c), del presente artículo deberá ser conducida sin dilación a la presencia de un juez o de otra autoridad habilitada por la ley para ejercer poderes judiciales, y tendrá derecho a ser juzgada en un plazo razonable o a ser puesta en libertad durante el procedimiento. La puesta en libertad puede ser condicionada a una garantía que asegure la comparecencia del interesado en juicio.

4. Toda persona privada de su libertad mediante detención preventiva o internamiento tendrá derecho a presentar un recurso ante un órgano judicial, a fin de que se pronuncie en breve plazo sobre la legalidad de su privación de libertad y ordene su puesta en libertad si fuera ilegal.

5. Toda persona víctima de una detención preventiva o de un internamiento en condiciones contrarias a las disposiciones de este artículo tendrá derecho a una reparación». Vid BOE núm. 243 , de 10/10/1979. 
recho (la privación de libertad) sólo serían admisibles en los supuestos estrictamente tasados y en las condiciones minuciosamente enumeradas y previstas en los párrafos siguientes de esta disposición, una aproximación claramente reforzada por la interpretación ofrecida por el TEDH.

El alcance de los conceptos de seguridad y libertad a los que se hace referencia han sido acotados por el propio Tribunal en el siguiente sentido: en relación con la seguridad, el derecho a la seguridad no significa la protección de ataques por parte de terceros; y en relación con el derecho a la libertad, su contenido se refiere a la libertad física y considera que dicho derecho queda comprometido desde el momento en que se produce cualquier tipo de pérdida de aquélla, con independencia de la denominación que reciba: arresto, internamiento, prisión, detención administrativa, prisión o detención preventiva, etc. Se considerará como tal incluso cuando un agente de la ley limite la libertad ambulatoria de una persona obligándola a permanecer en un determinado lugar o llegar hasta un determinado lugar, pues lo importante es el ejercicio de compulsión sobre esa persona, si bien la simple restricción de dicha libertad, ejercida dentro de unos límites y con las debidas garantías, no compromete el derecho per se, pues es necesario que se produzca una verdadera pérdida de libertad ${ }^{2}$.

El punto de partida y principio básico en el que descansa y desde el que se desarrolla la jurisprudencia del TEDH queda reflejado en la afirmación que éste realiza en el asunto Klass \& others $v$. Germany cuando, ante la adopción de determinadas medidas de vigilancia, en especial escuchas telefónicas y control de la correspondencia, adoptadas por el gobierno alemán como forma de prevenir el crimen en general y el espionaje y el terrorismo en particular, y declarándose consciente del aumento del terrorismo en las sociedades modernas, éste afirma otra necesidad paralela: la de limitar la acción de los Estados y de que los sistemas de vigilancia y control incluso secreto adoptados por éstos en la lucha contra el terrorismo se vean rodeados de las necesarias garantías, a fin de no destruir la democracia como consecuencia de la lucha por defenderla ${ }^{3}$.

De ello se deduce que, incluso si los Estados han intentado servirse al artículo 15 del $\mathrm{CEDH}^{4}$ para derogar en su favor ciertas obligaciones establecidas en

2 Vid asunto Engel \& others v. The Netherlands (Application n. ${ }^{\circ} 5100 / 71 ; 5101 / 71 ; 5102 / 71$; 5354/72; 5370/72, de 8 junio 1976), $\$ 58$; asunto Shamsa v. Poland (Application n. ${ }^{\circ}$ 45355/99; 45357/99, de 27 febrero 2004), $\$ 44$.

3 Vid asunto Klass \& others v. Germany (Application n. ${ }^{\circ}$ 5029/71, de 6 septiembre 1978), $\$ \$ 48-50$.

${ }^{4}$ El texto del artículo 15 del CEDH es el siguiente:

«1. En caso de guerra o de otro peligro público que amenace la vida de la nación, cualquier Alta Parte Contratante podrá tomar medidas que deroguen las obligaciones previstas en el presente 
el Convenio alegando una situación de emergencia nacional, ésta no ha sido aceptada por el TEDH en lo concerniente al artículo 5 del CEDH. O lo que es lo mismo, el derecho a la libertad y a la seguridad, en las condiciones previstas en dicho artículo, es inderogable a juicio del TEDH.

Así ha quedado claramente de manifiesto desde 1988 en asunto Brogan \& others $v$. The United Kingdom, en el que se impugnaba la posible violación de esta disposición en la detención de cuatro sospechosos de pertenencia al IRA al no haber sido conducidos ante la autoridad judicial competente en un plazo breve de tiempo, y sigue manteniéndose hoy, aún a pesar de los nuevos perfiles — si es que puede llamarse así- del terrorismo internacional y en claro contraste con las prácticas estatales más recientes, especialmente en relación con el llamado «imperativo de seguridad nacional $»^{5}$.

De acuerdo con estas premisas, ¿qué considera la jurisprudencia del $\mathrm{TEDH}$, sobre la base del artículo 5 del $\mathrm{CEDH}$, como detención o prisión pro-

Convenio en la medida estricta en que lo exija la situación, y supuesto que tales medidas no estén en contradicción con las otras obligaciones que dimanan del Derecho internacional.

2. La disposición precedente no autoriza ninguna derogación al artículo 2 , salvo para el caso de muertes resultantes de actos lícitos de guerra, y a los artículo 3, 4 (párrafo 1) y 7.

3. Toda Alta Parte Contratante que ejerza este derecho de derogación tendrá plenamente informado al Secretario General del Consejo de Europa de las medidas tomadas y de los motivos que las han inspirado. Deberá igualmente informar al Secretario General del Consejo de Europa de la fecha en que esas medidas hayan dejado de estar en vigor y las disposiciones del Convenio vuelvan a tener plena aplicación».

Por lo que hace al recurso a esta cláusula de derogación por parte de los Estados partes en el $\mathrm{CEDH}$ en relación con el terrorismo internacional, el Reino Unido ha hecho uso en diversas ocasiones de dicha facultad: en 1957, mediante comunicación de 20 de julio de 1957, en razón de su lucha contra el terrorismo del IRA (vid asunto Lawless v. Ireland (Application n. ${ }^{\circ} 332 / 57$, de 1 julio 1961), \$ 41); igualmente en 1984, mediante comunicación de 22 de agosto, por la misma razón (vid asunto Brogan \& others v. The United Kingdom (Application nos. 11209/84; 11234/84; 11266/84; 11386/85, de 30 mayo 1989), $\$ 48$ ); el 23 de diciembre de 1988, mediante el mismo procedimiento y por el mismo motivo (vid asunto Brannigan and McBride (Application n. ${ }^{\circ} 14553 / 89$; 14554/89, de 25 mayo 1993), $\$ 31$ ); y en 2001, como consecuencia de los ataques terroristas contra los EEUU, por considerar que el Reino Unido, como nación, se encontraba seriamente amenazada por el terrorismo internacional, lo que demandaba del Estado la adopción de medidas especiales que requerían del uso de este régimen derogatorio (vid asunto $A$ \& others $v$. United Kingdom (Application n. ${ }^{\circ}$ 3455/05, 19 febrero 2009), \$11). También Turquía, con ocasión de la lucha contra el terrorismo, ha utilizado esta posibilidad de derogación el 6 de agosto de 1990 (vid, entre otros, asunto Sakik \& others v. Turkey, cit. supra (Application n. ${ }^{\circ}$ 87/1996/67/897-902, de 26 noviembre 1997), $\$ 25$ ). Respecto de la derogación de las obligaciones establecidas en el CEDH mediante la utilización de la cláusula derogatoria del artículo 15 vid ALLAIN, J.: «Derogation from the European Convention of Human Rights in Light of "Other Obligations under International Law"», E.H.R.L.R. (2005-5), pp. 480-498.

5 Vid asunto $A \&$ others $v$. United Kingdom, cit. supra, $\$ \$ 171-172$. 
visional ajustada a derecho, en general, y en los supuestos de terrorismo en particular?

A la hora de responder a esta cuestión el TEDH ha sido categórico: para ser respetuosa con el $\mathrm{CEDH}$, toda detención debe, en primer lugar, ser justificable conforme a una o a varias de las causas o razones posibles previstas en el artículo 5 del CEDH, esto es, constituir detención en cumplimiento de una sentencia dictada por juez competente o en cumplimiento de una obligación establecida por ley; detención a fin de hacer comparecer y ser juzgado por la autoridad judicial competente; detención en espera de deportación o extradición; detención legal de un menor para vigilar su educación o comparecer ante la autoridad judicial competente; detención de persona alcohólica, toxicómana, vagabunda, enajenada o susceptible de contagiar una enfermedad contagiosa.

Si dejamos a un lado los dos últimos casos, que no tienen relevancia directa respecto del tema que nos ocupa, en el caso específico de detención en relación a la lucha contra el terrorismo es posible que el derecho a la libertad y a la seguridad se vea comprometido en tres situaciones diferentes: a) en el caso de ingreso en prisión tras sentencia condenatoria por parte de un tribunal competente; b) en el caso de detención por sospecha razonable de haber cometido una ofensa terrorista o para prevenir la comisión, por parte del detenido, de un acto terrorista; y c) en el caso de detención para impedir la entrada ilegal en el país o a efectos de deportación o extradición. A continuación se desarrollan los tres supuestos enunciados.

a) Por lo que hace al primero, éste no presenta elementos específicos o diferenciales cuando se refiere a la comisión de un acto u ofensa terrorista. Es la forma más directa de detención prevista por ley de las personas condenadas por sentencia judicial, sin que difiera de los demás supuestos penales: el tribunal juzgador ha de satisfacer, como en el resto de los casos, los requisitos de independencia e imparcialidad previstos en el artículo 6 del $\mathrm{CEDH}^{6}$.

b) Con respecto al segundo supuesto, que se refiere al caso de detención como consecuencia de la sospecha razonable de haber cometido un acto terrorista o estar dispuesto a cometerlo en el inmediato futuro, es preciso señalar que para determinar su legalidad son necesarios tres requisitos. En primer lugar, la ofensa con base en la cual se procede a la detención debe estar establecida legalmente como tal con carácter previo (principio de legalidad de los delitos y de

${ }^{6}$ Vid asunto Öcalan v. Turkey, (Application n. ${ }^{\circ} 46221 / 99$, de 12 de mayo 2005), \$\$ 114 y 116-118. 
las penas $)^{7}$, también en el caso de la lucha antiterrorista ${ }^{8}$. En segundo lugar, el objetivo de dicha detención debe ser llevar al detenido ante la presencia del juez competente, exigiéndose en este caso la diligencia debida por parte de la autoridad que detiene a la hora de la puesta a disposición judicial, y considerándose requisito esencial por parte de la amplia y rica jurisprudencia del TEDH precisamente en supuestos de actividades terroristas. Y, en tercer lugar, debe existir una sospecha suficientemente razonable para poder detener a una persona, sin que baste con la mera existencia de condenas anteriores del detenido en materia de terrorismo como la única base que justifique la detención?

La sospecha razonable requiere una justificación objetiva, aunque pueda estar en algún caso basada en la acción de informantes anónimos ${ }^{10}$. De acuerdo con la jurisprudencia del Tribunal, la existencia de sospechas plausibles que justifiquen suficientemente una decisión en caso de terrorismo supone la existencia de informaciones o de hechos capaces de persuadir a un observador objetivo de que el individuo en cuestión puede haber cometido la infracción que se sospecha, conforme al conjunto de circunstancias particulares del caso ${ }^{11}$, y ello

7 Vid, entre otros, el asunto Loukanov v. Bulgarie (Affaire n. ${ }^{\circ}$ 21915/93, de 20 marzo 1997), $\$ \$ 41,43-45$.

${ }^{8}$ Como quedó claramente de manifiesto en la sentencia condenatoria contra Turquía en un caso en el que ésta había aplicado, mediante la ficción de la figura del delito continuado, una pena más grave contenida en una legislación posterior a la comisión del delito en cuestión (pertenencia a organización terrorista, en este caso el PKK, asistencia personal a miembros del grupo terrorista y ayuda técnica y logística a la organización): «(...) The Court recalls that the guarantee enshrined in Article 7 , which is an essential element of the rule of law, occupies a prominent place in the Convention system of protection, as is underlined by the fact that no derogation from it is permissible under Article 15 in time of war or other public emergency. It should be construed and applied, as follows from its object and purpose, in such a way as to provide effective safeguards against arbitrary prosecution, conviction and punishment (...) It can reasonably be considered that the applicants prepared their defence in response to the charges defined in the bill of indictment and against the background of the sanction which they risked incurring if found guilty as charged (...) In these circumstances, the Court concludes that the applicants were subjected to the imposition of a heavier sentence under the 1991 Act than the sentence to which they were exposed at the time of the commission of the offence of which they were convicted (...)" (vid asunto Ecer and Zeyrek v. Turkey (Applications nos. 29295/95 y 29363/95, de 27 febrero 2001), \$\$ 29, 35-36).

9 Vid asunto Fox, Campbell and Hartley v. The United Kingdom (Application n. ${ }^{\circ}$ 12244/86; $12245 / 86 ; 12383 / 86$, de 30 agosto 1990), $\$ 35$.

${ }^{10} \mathrm{Vid}$ al respecto los asuntos Doorson v. The Netherlands (Application n. ${ }^{\circ}$ 20594/92, de 26 marzo 1996), $\$ 69$; y Van Mechelen v. The Netherlands (Application n. ${ }^{\circ} 21363 / 93 ; 21364 / 93$; 21427/93, de 23 abril 1997), siguiendo la jurisprudencia sentada al respecto en los asuntos Kostovski v. The Netherlands (Application n. ${ }^{\circ} 11454 / 85$, de 24 noviembre 1989), $\$ 44$, y Windisch $v$. Austria (Application n. ${ }^{\circ}$ 12489/86, de 27 septiembre 1990), $\$ 30$.

11 Vid asunto Fox, Campbell and Hartley v. The United Kingdom, cit. supra, $\$ \$ 31-32$.

12 Vid ibíd., $\$ 34$. 
aún admitiendo que las actividades terroristas merecen una consideración especial, por la específica problemática que acarrean ${ }^{12}$.

No basta con interrogar de buena fe a los detenidos con antecedentes terroristas, ni el hecho de que se haya preguntado a los detenidos durante el interrogatorio por hechos terroristas concretos; ello puede satisfacer el criterio de razonabilidad de la sospecha de haber cometido probablemente esos hechos a los ojos de la policía, pero no de un observador objetivo ${ }^{13}$. Este hecho podría, en su caso, dulcificar la rigidez de los requisitos probatorios dependiendo del caso concreto, como ocurrió en el asunto Murray v. The United Kingdom, en el supuesto de un matrimonio arrestado bajo sospecha de recaudar fondos para el IRA, pero no podrá nunca poner en peligro la protección del núcleo duro del derecho en cuestión $^{14}$. En todo caso, todas estas precisiones en torno a la razonabilidad a la hora de detener a una persona sospechosa de la comisión de actos terroristas, han permitido al Tribunal construir una cierta teoría general, desde el punto de vista de los requisitos probatorios.

Todas las matizaciones hasta aquí establecidas por el TEDH deben considerarse extensibles en el supuesto de que la detención de una persona, bajo sospecha de comisión de las infracciones más graves, en especial de terrorismo, se produzca en el extranjero, como ha puesto de manifiesto el asunto Öcalan v. Turkey, con la detención de este activista turco del PKK en Kenya, perseguido por Turquía para ser juzgado, entre otras causas, por creación de banda armada y atentados terroristas con fines separatistas ${ }^{15}$, un aspecto de especial trascendencia dado que este tipo de acciones se han generalizado tras los atentados del 11-S.

Que la detención se base en una sospecha razonable no implica que el agente que procede a la detención comunique todas y cada una de las razones en las que dicha sospecha se basa al detenido en el momento de la detención, como se verá más delante. Por otro lado, las detenciones «en blanco», esto es, sin causa justificada, difícilmente satisfarán el criterio de la proporcionalidad. La posibilidad de detener a una persona bajo sospecha razonable de haber cometido una ofensa terrorista, no puede ser utilizada para autorizar una política general de detención preventiva sobre la base de la mayor propensión del detenido a la comisión de dichas ofensas. Para poder basar la detención en tal sospecha razonable, la ofensa en cuestión ha de ser específica y tener individualidad propia. Por supuesto, la detención bajo sospecha razonable de comisión de un delito te-

13 Vid ibíd., $\$ 37$.

${ }_{14}$ Vid asunto Murray v. The United Kingdom (Application n. ${ }^{\circ} 14310 / 88$, de 28 octubre 1994), $\$ 51$; igualmente significativos resultan a este respecto $\$ \$ 58,61$ y 63 .

15 Vid asunto Öcalan $v$. Turkey, cit. supra, en especial $\$ \$ 91$ y ss. 
rrorista conlleva la supervisión judicial y otras garantías procesales, conforme al artículo 5 del CEDH.

c) Para finalizar, y en relación con el tercero de los supuestos antes enumerados — esto es, la detención con el fin de deportar o extraditar al detenido-, el derecho a la libertad consagrado en el CEDH permite la detención de un individuo que se encuentra en espera de ser extraditado o deportado como consecuencia, por ejemplo, de la denegación de su solicitud de asilo. En este sentido, los intentos de deportar o extraditar a esta persona deben ser genuinos, y no una simple excusa para mantener a la persona en cuestión en prisión, y encontrarse en proceso de culminación. Sin embargo, y especialmente relevante en el caso de medidas en relación a la lucha contra el terrorismo, si la deportación o la extradición son imposibles, la detención no podrá estar justificada conforme al artículo 5 del CEDH. En este sentido, el TEDH ha mantenido que el hecho de que un individuo sea detenido por un período de tiempo indeterminado e imprevisible, sin que tal detención esté basada en una disposición jurídica específica o en una decisión judicial válida, es contrario al principio de seguridad jurídica, implícito en el Convenio y elemento fundamental del Estado de derecho ${ }^{16}$.

Finalmente, la detención puede venir aún justificada como medida para cumplir con una orden judicial que, a su vez, implementa una obligación establecida legalmente. Sin embargo, estas situaciones difícilmente van a producirse en el supuesto de medidas o estrategias de lucha antiterrorista, aunque en casos puntuales puedan ser relevantes. La detención para asegurar el cumplimiento de cualquier obligación establecida por ley requiere igualmente especificidad, y no puede ser utilizada para justificar la prisión preventiva. Como tal, al considerar si la detención se realiza conforme a derecho, esta disposición ha de ser interpretada de forma restrictiva y no puede ser utilizada para justificar una detención que de otra forma no cumpliría con las causas de detención justificadas establecidas en el artículo 5 del CEDH en relación con el derecho a la libertad. Así pues, deben existir razones concretas y específicas para proceder a dicha detención.

\section{CONDICIONES DE LA DETENCIÓN EN LOS CASOS DE TERRORISMO}

Una vez establecidas en el artículo 5.1 del CEDH las causas tasadas y de interpretación restrictiva por las que una persona puede ser privada de su liber-

${ }^{16}$ Vid asunto Shamsa v. Poland, cit. supra, $\$ 49$. 
$\operatorname{tad}^{17}$, los siguientes párrafos de esta misma disposición establecen una se rie de condiciones que deberán ser respetadas en todo caso a la hora de dicha privación de libertad, independientemente de su modalidad.

En este sentido el TEDH se ha mantenido firme a la hora de rechazar las argumentaciones de los Estados contratantes que defienden que el artículo 5.1 permite calibrar el derecho a la protección de la libertad del individuo frente a la obligación del Estado de dar protección a su población ante la amenaza terrorista. El TEDH ha considerado este argumento inconsistente no sólo con la jurisprudencia desarrollada en relación al artículo 5.1 f), sino además con la afirmación de que la lista de condiciones limitativas al derecho a la libertad y la seguridad establecida en los apartados a) a f) del artículo 5 es exhaustiva y de obligada interpretación restrictiva. Si la detención no se ajusta a los confines fijados por el artículo 5 tal y como éstos han sido interpretados por el TEDH, tampoco puede ser aceptable recurriendo al argumento del necesario balance — en el sentido de ajuste- entre el derecho del detenido y la obligación de proteger del Estado ${ }^{18}$.

Al realizar esta afirmación tan tajante el Tribunal no es ajeno a la situación que afrontan los gobiernos y, precisamente por eso, ha aceptado ampliamente el derecho de los Estados de derogar algunas de sus obligaciones utilizando la vía del artículo 15 del CEDH, cuya revisión, no obstante, se ha reservado. Así, el alto órgano jurisdiccional ha recordado que corresponde a cada Estado miembro determinar, en el marco de su responsabilidad de proteger la vida de la nación, si esa vida se encuentra amenazada por una "emergencia pública» y, en tal caso, hasta dónde deben llegar a fin de combatirla. Dado su contacto directo y continuo con la presión que sin duda ejercen las necesidades de cada momento, las autoridades nacionales están en principio, a juicio del Tribunal, mejor capacitadas que el juez internacional para decidir tanto acerca de la presencia de tal amenaza o emergencia como sobre la naturaleza y el alcance de las medidas necesarias para superarla.

Consiguientemente, debe reconocerse un amplio margen de actuación a las autoridades nacionales a este respecto, pero en ningún caso un poder discrecional ilimitado. Por tanto, el margen de apreciación que se reconoce a las partes contratantes y la compatibilidad de dicha exoneración con los límites que

17 En este sentido el TEDH ha recordado que la lista de causas posibles de privación de libertad establecidas en el artículo 5 del $\mathrm{CEDH}$ es exhaustiva y de interpretación restrictiva de forma constante desde el asunto Ireland $v$. The United Kingdom (Application n. ${ }^{\circ}$ 5310/71, de 18 enero 1978$), \$ 194$.

${ }^{18}$ Ibíd., $\$ 171$. 
marca el CEDH quedan siempre bajo la supervisión del TEDH ${ }^{19}$. Y de acuerdo con la evolución mostrada por la jurisprudencia de éste, es posible afirmar que, en la actualidad, el TEDH considera el derecho a la libertad y la seguridad, así como el derecho a un juicio justo, como derechos inderogables.

Cualquiera que sea la forma que las medidas nacionales de lucha contra el terrorismo adopten, en la práctica totalidad de los casos presentados ante el TEDH los Estados plantean de forma directa o indirecta una extensión de los poderes relacionados con la detención por parte de las correspondientes autoridades nacionales y/o, en algunos casos, la reducción de los controles o garantías que la rodean ${ }^{20}$. En este sentido los Estados, a la hora de reforzar la lucha antiterrorista, ponen el acento en caracterizar la violencia terrorista no sólo como ilegítima, sino también como criminal. Por otro lado, las autoridades nacionales competentes en materia de terrorismo afrontan obstáculos importantes a la hora de obtener condenas criminales en casos de terrorismo, que están directamente relacionados con las características especiales de este tipo de delito (modos específicos de comisión y/o participación, medios de prueba, etc.). Así, como se ha puesto muy acertadamente de manifiesto, en el corazón del dilema del Estado a la hora de planificar y reforzar la lucha antiterrorista, se encuentra la tensión entre la retórica de la criminalidad y la realidad de la lucha antiterrorista en la práctica $^{21}$. En algunos casos, y en el marco del proceso penal, los Estados han considerado esencial conceder prioridad a la necesidad de detener a los sospechosos de actos terroristas por encima del respeto de los derechos fundamentales - en general, o de los terroristas o sospechosos de tal en particular-, sirviéndose de forma recurrente de una forma de detención preventiva al margen de las garantías previstas en el artículo 5 del $\mathrm{CEDH}$, un recurso que, como se ha mencionado, sólo puede ser utilizado mediante el recurso a la cláusula deroga-

19 Vid asunto Ireland $v$. The United Kingdom, cit. supra, $\$ 214$, reiterado profusamente en toda la jurisprudencia posterior.

20 Se trata de una característica común también a situaciones históricas de lucha contra el terrorismo internacional, en la medida en que los Estados en el pasado han recurrido sistemáticamente al argumento de que el terrorismo supone una amenaza excepcional que sirve de justificación a sus gobiernos para adoptar medidas también excepcionales que no serían posibles en un tratamiento regular desde el punto de vista de los ordenamientos jurídicos penales para otras formas de criminalidad, y que pueden poner seriamente en riesgo los fundamentos del Estado de Derecho. Vid a este respecto el Informe de la Comisión Internacional de Juristas, Assessing damage, Urging Action. Report of the Eminente Jurists Panel on Terrorism, Counter-Terrorism and Human Rights, Ginebra, 2009, en especial vid, pp. 22 y 69.

${ }^{21}$ Vid WARBRICK, C.: «The Principles of the European Convention on Human Rights and the Response of States to Terrorism», E.H.R.L.R. (2002-3), pp. 287-314, en especial vid p. 298. 
toria del artículo 15, siempre que el Estado en cuestión desee y esté dispuesto a hacer tal declaración de emergencia respetuosa con los límites previstos ${ }^{22}$.

El derecho a la libertad garantiza un número de salvaguardias en favor de aquellos que afrontan un procedimiento penal. Estas garantías, mínimas por otra parte e inherentes al concepto de Estado de Derecho ${ }^{23}$, son igualmente de aplicación obligatoria cuando el procedimiento penal abierto tiene como base una ofensa terrorista, por lo que los Estados no pueden evitar aplicarlas reclasificando la detención como "administrativa» en lugar de como "penal» ${ }^{24}$. En este sentido la definición del procedimiento como criminal o penal es un concepto autónomo, por lo que los tribunales no se encuentran vinculados por la denominación que las autoridades estatales confieran a la detención operada, disponiendo de toda su competencia para establecer la naturaleza penal o administrativa de hecho del procedimiento y, consiguientemente, de la detención.

Y establecida la naturaleza penal del procedimiento, si las circunstancias de la detención preventiva o administrativa no pueden venir justificadas en ninguna de las seis causas previstas en el artículo 5 del CEDH, será considerada como contraria a derecho. El Estado que pretenda llevar a cabo detenciones por motivos diferentes a las seis causas tasadas recogidas en dicha disposición debería justificar debidamente una derogación de sus obligaciones en materia de derechos humanos. Incluso si la detención es admisible desde el punto de vista jurídico y conforme con la derogación realizada por el Estado en cuestión, ésta debe quedar sometida en todo caso al escrutinio de un tribunal independiente e imparcial.

En este sentido el TEDH, desde el primer caso relacionado con las formas nacionales de lucha contra el terrorismo internacional y su compatibilidad con la protección de los derechos humanos, el asunto Lawless $v$. Ireland, ha sostenido que la detención administrativa sin supervisión judicial viola del derecho fun-

${ }^{22}$ Límites que han sido recordados por el TEDH, en el caso de situación de emergencia nacional por terrorismo, entre otros, en los asuntos Lawless v. Ireland, cit. supra, $\$ \$ 28$ y ss, o Sakik \& Others v. Turkey, cit. supra, $\$ 39$.

${ }^{23}$ Vid a este respecto SUDRE, F., MARGUENAUD, J.P ., ANDRIANTSIMBAZOVINA, J. GOUTTENOIRE, A. y LEVINET, M.: Le grands arrêts de la Cour européenne des Droits de l'Homme, París, 2009, pp. 63 y ss.

${ }^{24}$ Especialmente importantes a este respecto son las «control orders» británicas establecidas por la Prevention Terrorism Act 2005, concediendo la posibilidad tanto a los tribunales de justicia como al Secretario de Estado de interior británico de imponer una serie de obligaciones a ciertas personas sospechosas de estar involucradas en actividades terroristas sin que este extremo se pudiera demostrar, no permitiendo por tanto su procesamiento, pero limitando muy seriamente su libertad. Vid al respecto STARMER, K: «Setting the Record Straight: Human Rights in an Era of International Terrorism», E.H.R.L.R. (2007-2), pp. 123-132. 
damental del individuo a la libertad y puede ser contraria también al derecho a un juicio justo, protegido igualmente por el artículo 6 del $\mathrm{CEDH}$, incluso si en dicho supuesto ambas violaciones potenciales estaban contempladas y autorizadas por la derogación realizada por el Estado miembro en cuestión con base en el artículo 15 del CEDH. La garantía de la revisión judicial de la detención ha sido considerada como fundamental por el TEDH y aplicable a todo tipo de detención, en general, y en el ámbito de la lucha contra el terrorismo en particular, como lo reconoció de forma contundente el Tribunal ya en $1961^{25}$. Una jurisprudencia que ha sido ratificada posteriormente en el asunto Ireland $v$. The United Kingdom, y a cuyo razonamiento el TEDH ha añadido aún una precisión más, también de vital importancia en el contexto de la «guerra» contra el terrorismo de los últimos años, a saber, que no es posible interpretar que el artículo 5.1.b) del CEDH pueda amparar un poder general de detención preventiva en favor de los Estados.

A continuación se analizan los principales elementos y circunstancias relacionadas con las condiciones de la detención y sus garantías procesales, al margen de las propias causas de detención que se encuentran enumeradas en el artículo 5 del CEDH y que se deben cumplir exhaustivamente aún cuando la duración de ésta sea muy breve, a la luz de la jurisprudencia emanada del alto Tribunal.

a) El TEDH ha exigido que las razones que justifican la detención en cuestión deben ser expuestas de forma detallada y con celeridad, y esos criterios son aplicables a toda detención, incluidos también los supuestos de terrorismo.

No obstante, este requisito no impone la obligación de dar cuenta de forma inmediata de todas las razones que justifican la detención, como ha observado el Tribunal $^{26}$. Hay que tener en cuenta, además, la especial dificultad que los delitos terroristas comportan a este respecto. De este modo, en el caso de arresto o detención de sospechosos de terrorismo unas horas pueden marcar la diferencia, habida cuenta de la necesidad de tomar en consideración razones de seguridad nacional ${ }^{27}$. Además, en muchos de estos casos la persona que procede a la detención puede basar sus sospechas en informaciones fidedignas, pero que no pueden ser comunicadas de inmediato al detenido ${ }^{28}$.

${ }^{25}$ Vid asunto Lawless $v$. Ireland, cit. supra, $\$ 14$.

${ }^{26}$ Vid asunto O'Hara v. The United Kingdom (Application n. ${ }^{\circ} 37555 / 97$, de 16 octubre 2002), $\$ 36$.

${ }^{27}$ Vid asunto Dikme et autres c. Turquie (Requête n. ${ }^{\circ}$ 20869/92, de 11 julio 2000), \$\$ 61-64.

${ }^{28}$ Vid ibíd., $\$ 35$. 
De otro lado, no es suficiente con informar de la detención de las personas afectadas bajo la justificación de la aplicación de medidas especiales de emergencia, sino que es necesario ofrecer razones concretas que, para cumplir con las garantías ofrecidas por el Convenio ${ }^{29}$, habrán de ser dadas en un lenguaje sencillo, no técnico y en un idioma comprensible para el detenido ${ }^{30}$. A este respecto la edad y el estado mental del detenido deberán ser tomados en cuenta a efectos de valorar su capacidad de comprensión o, incluso, la posibilidad de informar rápidamente a una tercera persona responsable del detenido/a, en caso de incapacidad, de las razones de la detención.

b) El TEDH ha sido muy riguroso a la hora de enjuiciar las razones que justifican el retraso en la puesta a disposición judicial de los detenidos bajo sospecha de comisión de una ofensa terrorista. También en este caso se presume la puesta a disposición judicial lo más rápida posible del sospechoso, ante un tribunal que tenga competencia, en su caso, para decidir su puesta en libertad; en este sentido la sola competencia para recomendar la puesta en libertad, pero no para decretarla, no ha sido considerada como suficiente por la jurisprudencia del Tribunal ${ }^{31}$.

De acuerdo con el criterio de la rapidez ("promptness»), detener a una persona, por ejemplo, durante cuatro días y seis horas antes de ponerlo a disposición judicial fue considerado excesivo por el Tribunal ${ }^{32}$, aún en una situación en la que se trataba de la sospecha de la comisión de un atentado terrorista y que implicaba razones de seguridad nacional. E incluso, en el caso de haber sido aceptada la derogación de las obligaciones de la CEDH como consecuencia de

${ }^{29}$ Como afirma de forma rotunda el TEDH en el asunto Tomasi: «(...) The Court accepts that, by reason of their particular gravity and public reaction to them, certain offences may give rise to public disquiet capable of justifying pre-trial detention, at least for a time. In exceptional circumstances — and subject, obviously, to there being sufficient evidence (...) — this factor may therefore be taken into account for the purposes of the Convention, in any event in so far as domestic law recognises (...) the notion of prejudice to public order caused by an offence. However, this ground can be regarded as relevant and sufficient only provided that it is based on facts capable of showing that the accused's release would actually prejudice public order. In addition, detention will continue to be legitimate only if public order remains actually threatened; its continuation cannot be used to anticipate a custodial sentence (...) In the present case, the investigating judges and the indictments divisions assessed the need to continue the deprivation of liberty from a purely abstract point of view, merely stressing the gravity of the offences (...) nor their effects (...)". Vid asunto Tomasi v. France (Application n. ${ }^{\circ}$ 12850/87, de 27 agosto 1992), \$91.

${ }^{30}$ Vid asunto Conka v. Belgium (Application n. ${ }^{\circ}$ 51564/99, de mayo 2002), $\$ 50$.

31 Vid asunto Ireland $v$. The United Kingdom, cit. supra, $\$ 200$.

32 Vid asunto Brogan \& others v. The United Kingdom, cit, supra, $\$ 62$. 
una situación de emergencia que amenazase la vida de la nación (artículo 15 del $\mathrm{CEDH})$, el TEDH consideró inadmisible que la puesta a disposición judicial se produjese tras 14 días de detención ${ }^{33}$.

En todo caso el Tribunal, consciente de las diferencias entre la versión francesa ("aussitôt») e inglesa ("promptly») de la Convención, ha aceptado que la interpretación de la versión inglesa ("promptly») pueda ser más amplia que la francesa interpretada de forma individualizada caso a caso, y ha establecido, no obstante, que incluso admitiendo dicha interpretación amplia, ésta nunca puede atentar contra la esencia misma del derecho garantizado. Además, el TEDH ha establecido que la existencia y persistencia de serios indicios de la culpabilidad de la persona concernida constituyen indudablemente factores relevantes, pero el Tribunal no considera que puedan ellos solos justificar un período tan largo de detención sin puesta a disposición judicial ${ }^{34}$.

Qué debe considerarse como rápido depende, pues, de las circunstancias de cada caso, si bien no necesariamente debe entenderse como inmediato. Sí es im-

33 En este sentido el TEDH ha subrayado que: «(...) it falls to each Contracting State, with its responsibility for the "life of [its] nation", to determine whether that life is threatened by a "public emergency' and, if so, how far it is necessary to go in attempting to overcome the emergency. By reason of their direct and continuous contact with the pressing needs of the moment, the national authorities are in principle better placed than the international judge to decide both on the presence of such an emergency and on the nature and scope of the derogations necessary to avert it. Accordingly, in its matter a wide margin of appreciation should be left to the national authorities. Nonetheless, Contracting Parties do not enjoy an unlimited discretion. It is for the Court to rule whether, inter alia, the States have gone beyond the "extent strictly required by the exigencies" of the crisis. The domestic margin of appreciation is thus accompanied by a European supervision. In exercising this supervision, the Court must give appropriate weight to such relevant factors as the nature of the rights affected by the derogation and the circumstances leading to, and the duration of, the emergency situation (...)». Vid asunto Aksoy v. Turkey (Application n. ${ }^{\circ} 21987 / 93$, de 18 diciembre 1996), $\$ \$ 68$ y 78.

En otros asuntos los plazos considerados inadmisibles han sido por ejemplo de ocho días, en el asunto Filziz and Kalkan v. Turkey (Application n. ${ }^{\circ} 34481 / 97$, de 20 junio 2002), $\$ 25$; o bien once días en el asunto Sadak c. Turquie (Requêtes n. ${ }^{\text {os }} 25142 / 94$ y 27099/95, de 8 abril 2004), $\$ 62$; o de diez días, en el asunto Sakik et autres v. Turkey (Requête 87/1996/706/898-903, de 26 noviembre 1997), $\$ \$ 44-45$; o de dieciséis días, en el asunto Dikme et autres c. Turquie, cit. supra, $\$ \$$ 61-63. Aún existen supuestos de detención preventiva de siete años y siete meses, como el asunto Kamil Öcalan c. Turquie (Requête n. ${ }^{\circ}$ 20648/02, de 12 diciembre 2006), \$\$30-31; o de cinco años y dos meses en el asunto Hasan Ceylan v. Turkey (Application n. ${ }^{\circ}$ 58398/00, de 23 agosto 2006), $\$ 28$. El TEDH ha considerado igualmente excesiva la detención policial sin comparecencia ante un juez de un detenido durante diez días, incluso si siete de ellos ha permanecido ingresado en un centro médico (vid asunto Soysal c. Turquie (Requête n. ${ }^{\circ}$ 50091/99, de 3 agosto 2007), \$ 75). En el mismo sentido, en genera, vid asunto Aerts v. Belgium (61/1997/845/1051, de 30 julio 1998), y asunto Kudla v. Poland (Application n. ${ }^{\circ} 30210 / 96$, de 26 octubre 2000).

34 Vid asunto Tomasi v. France, cit. supra, $\$ 89$.

N. ${ }^{\circ} 79$, septiembre-diciembre 2010, págs. 285-333 
prescindible, en todo caso, dar a conocer las razones de la detención, pues sin éstas es imposible impugnar, mediante el procedimiento apropiado en cada caso, la legalidad de la detención, otra de las garantías procesales irrenunciables establecidas por el artículo 5 del CEDH, como se verá más adelante.

c) De otra parte, la detención debe venir autorizada por un tribunal u otra autoridad habilitada por la ley para ejercer poderes judiciales. Para satisfacer necesariamente las garantías procesales que rodean el derecho a la libertad, la autoridad habilitada debe ser independiente del ejecutivo y ser imparcial ${ }^{35}$, así como disponer de competencias para ordenar, en su caso, la puesta en libertad del detenido.

En suma pues, la garantía de llevar al detenido ante una autoridad judicial con celeridad cumple tres funciones protectoras esenciales: deja constancia de que el detenido se encuentra bajo la custodia del Estado; permite al juez conocer cualquier tipo de alegación relativa a malos tratos o detención en condiciones adversas $^{36}$, así como valorar la condición del detenido, lo que normalmente desemboca en la autorización, a partir de ese momento, de las comunicaciones entre éste y su abogado.

Esta garantía debe suponer, además, que el detenido ha de ser juzgado en un período razonable de tiempo, conforme al artículo 5.3 del CEDH, y ni la complejidad de las investigaciones como consecuencia de tratarse de una ofensa terrorista, ni el número de personas implicadas, ni la existencia y persistencia de serios indicios de la culpabilidad del detenido, que son sin duda factores relevantes, pueden justificar sin embargo un periodo más largo de detención, como tuvo ocasión el TEDH de afirmar en el asunto Tomasi v. France, a la vista de la detención de un sospechoso de participación en un atentado terrorista, cometido por un grupo independentista corso, durante un período de cinco años y siete meses $^{37}$. A este respecto el TEDH ha recordado a los Estados que en aquellos casos en los que se pretenda alargar la presencia del detenido en prisión, será necesario que la autoridad judicial competente fundamente con razones claras y adecuadas dicha permanencia, no siendo suficiente una reiteración automática de razones genéricas ${ }^{38}$. Y es que, como el Tribunal ha afirmado, si bien la detención

${ }^{35}$ Vid asunto Kamil Öcalan c. Turquie, cit. supra, $\$ 114$.

36 Vid asunto Dikme et autres $c$. Turquie, cit. supra, $\$ 66$.

37 Vid asunto Tomasi v. France, cit. supra, $\$ \$ 83,89$ y 102 . Así ha sido reiterado en diversos asuntos, como por ejemplo en el asunto Demir et autres c. Turquie (71/1997/855/1062-1064, de 23 septiembre 1998), $\$ 43$.

38 Vid asunto Kamil Öcalan c. Turquie, cit. supra, , $\$ 32$. 
de una persona en un primer momento, y como consecuencia del imperativo de orden público en el caso específico de la lucha contra el terrorismo, haya podido producirse por un período excepcionalmente largo, la inminencia de la amenaza de aquel momento inicial disminuye necesariamente con el tiempo ${ }^{39}$.

d) Otra de las condiciones establecidas por el artículo 5 del CEDH, a fin de que la detención pueda ser considerada como compatible con el derecho a la libertad, es que toda detención con carácter previo al juicio debe ser justificada, independientemente de su duración, incluso si se trata de un período muy breve, de la misma manera que toda detención preventiva o previa al juicio debe estar bajo supervisión judicial. Además, el TEDH ha afirmado, en primer lugar, que es esencial la presunción de inocencia a favor del detenido ${ }^{40}$; en segundo lugar, que el detenido no tiene ninguna obligación de ayudar a las autoridades en su enjuiciamiento ${ }^{41}$, incluso si se ha de reconocer que esa falta de colaboración puede afectar a la rapidez del proceso, siendo así que el derecho «a un juicio en un período razonable de tiempo» depende de las circunstancias del $\operatorname{caso}^{42} ; \mathrm{y}$, en tercer lugar, que a la hora de interpretar dicha disposición, debe entenderse que existe una presunción a favor de la puesta en libertad bajo fianza, cuya adopción debe ser considerada tan pronto como sea posible ${ }^{43}$.

39 Vid asunto Gérard Bernard c. France (Requête n. ${ }^{\circ}$ 27678/02, de 26 diciembre 2006), $\$ 46$. En el mismo sentido, en el asunto Bati, el TEDH ha afirmado: «(...) En l'ocurrence, il ressort des éléments du dossier que la cour de sûreté de l'État a ordonné le maintien en détention des requérants en utilisant presque toujours des formules identiques, telles que "compte tenu de la nature du crime reproché et de l'état des preuves", pour ne pas dire stéréotypées, et, au moins à deux reprises, sans en indiquer de motifs. Ces motivations se référaient à la globalité des détenues et se bornaient à mentionner abstraitement la nature du crime en cause (...) Elles ne révélaient aucune considération susceptible d'étayer le fondement des risques évoqués et n'en établissaient pas la réalité par rapport aux requérants. Elles ne tenaient pas compte de ce que les accusations dirigées contre les requérants reposaient sur des éléments qui, au fil du temps, saffaiblissaient au lieu de se renforcer (...)». Vid asunto Bati et autres c. Turquie (Requêtes n. ${ }^{\text {os } 33097 / 96}$ y 57834/00, de 3 septiembre 2004), \$ 162).

40 Vid asunto Kamil Öcalan c. Turquie, cit. supra, $\$ 31$; y el asunto Hasan Ceylan v. Turkey, cit. supra, $\$ 23$.

${ }^{41}$ A este respecto el derecho a no autoinculparse, a no declarar contra sí mismo, ha sido también establecido en materia de terrorismo. Vid asunto O'Halloran and Francis v. The United Kingdom (Applications n. ${ }^{\text {os }}$ 15809/02 y 25624/02, de 29 junio 2007), $\$ 49$.

${ }_{42}$ Vid asunto Dikme et autres $c$. Turquie, cit. supra, $\$ 56$, en el que la utilización de identidad falsa por parte del detenido había contribuido a prolongar el retraso en la información de los motivos que justificaban su detención no obstó para que el TEDH entendiese que se había producido violación del artículo 5.2 del CEDH.

$43 \mathrm{Tal}$ y como el TEDH ha tenido ocasión de afirmar: «(...) le substance même du paragraphe 3 de cette disposition est le droit de rester libre dans l'attente d'un procès pénal. Cette disposition ne peut 
El Tribunal ha aceptado como posibles causas para rechazar la puesta en libertad bajo fianza las siguientes: riesgo de fuga del detenido, interferencia con la acción de la justicia, prevención de nuevas ofensas o ilícitos, preservación del orden público o la propia protección del detenido. En todo caso la puesta en libertad bajo fianza debe ser aplicada con preferencia a la prisión preventiva; ahora bien, las condiciones establecidas para su disfrute no pueden ser abusivas, pues se trata tan sólo de asegurar, mediante dichas condiciones, la presencia del detenido, lo que dependerá de cada caso en cuestión. A este respecto el Tribunal ha aceptado, entre las condiciones posibles, la comparecencia periódica ante autoridad policial o judicial y/o la retirada del pasaporte.

e) El derecho a impugnar la legalidad de la detención, o habeas corpus, incorporado como límite en el artículo 5.4, ofrece una protección especial a los detenidos, y en la actualidad constituye un derecho considerado como inderogable tanto por el Consejo de Derechos Humanos de UN como por la Corte Interamericana de Derechos Humanos ${ }^{44}$.

El derecho al habeas corpus cumple un papel esencial a la hora de asegurar el respeto de la vida y de la integridad física de la persona detenida, la no desaparición de ésta, o en mantener en secreto toda la información confidencial en relación al detenido y en protegerle contra cualquier tipo de tortura o trato cruel inhumano o degradante. El TEDH ha establecido igualmente la necesidad de adoptar medidas de salvaguarda especiales en el caso de determinadas categorías de detenidos como mujeres, jóvenes, ancianos, extranjeros, minorías étnicas o enfermos mentales.

Respecto de la condición inderogable de este derecho, el TEDH ha establecido un claro punto de partida, al recordar, en el caso de dos detenidos por las autoridades turcas bajo sospecha de pertenencia a grupo terrorista, que en todo caso debe existir una vía interna de recurso con un grado de certeza suficiente, además de la accesibilidad y la eficacia requeridas por el art. 5.45 el Tribunal que la ausencia de precedentes judiciales en el Estado en cuestión re-

pas être comprise comme offrant aux autorités judiciaries une option entre jugement dans un délai raisonnable et mise en liberté provisoire, éventuellement subordonnée à des garanties. L'objet de l'article 5 $\$ 3$ est essentiellement d'imposer la mise en liberté provisoire à partir du moment où le maintien en détention cesse d'être raisonnable (...)". Vid asunto Shabani c. Suisse (Requête n. . 29044/06, de 5 noviembre 2009), $\$ 54$. En el mismo sentido vid asunto McKay v. The United Kingdom (Application n. ${ }^{\circ} 543 / 03$, de 3 octubre 2006), $\$ 43$.

44 Vid al respecto ALLAIN, J., cit. supra, y la jurisprudencia allí citada.

45 Vid asunto Mamaç et autres c. Turquie (Requêtes n. ${ }^{\text {s }} 29486 / 95$, 29487/95 y 29853/96, de 20 julio 2004), $\$ 41$. 
conociendo esta posibilidad de facto a favor de los detenidos equivale a la ausencia de tal garantía ${ }^{46}$.

La decisión judicial que se pronuncie sobre la detención debe incorporar el derecho a la revisión. Las sentencias en materia de detención que no hayan fijado el término de la misma deben ser recurribles por el mismo procedimiento; así mismo, la capacidad de revisión exigible a la autoridad judicial que ejerce el $h a-$ beas corpus dependerá de las circunstancias de cada supuesto pero, en todo caso, la autoridad judicial debe tener competencia para revisar la legalidad de la detención, debe ser independiente e imparcial tanto desde un punto de vista subjetivo como estructural de la autoridad que haya ordenado la detención y ha de tener competencia para adoptar decisiones jurídicamente vinculantes. Sin embargo, dicha revisión no necesariamente ha de llevarse a cabo mediante un procedimiento público, si bien deberá hacerse siempre en el marco de un procedimiento basado en los principios de contradicción e igualdad de armas en el marco del cual la autoridad que ha procedido a la detención demuestre la legalidad de la misma y en el que el detenido reciba asistencia legal en caso de ser necesaria $^{47}$.

Por otro lado, el TEDH ha exigido, a favor del detenido, la posibilidad de impugnar periódicamente, a intervalos razonables, la legalidad de la detención. El derecho a dicha impugnación, conforme a la jurisprudencia del TEDH, se aplica a todas las personas privadas de libertad y no sólo a aquellas detenidas bajo sospecha de haber cometido un ilícito.

f) En íntima conexión con el derecho al habeas corpus y para que éste pueda ser efectivamente ejercido, el detenido necesitará en su caso de la representación y consejo de un abogado, un elemento que plantea especiales problemas en el caso de la lucha contra el terrorismo, dada la protección a la que de ordinario las autoridades nacionales someten toda información relativa a los hechos, investigaciones e incluso acusaciones posibles contra el detenido, todo ello, como se arguye con frecuencia, por el «imperativo de la seguridad nacional». Ahora bien, la falta de comunicación de los motivos de la detención al detenido y a su abogado, representante legal o consejero jurídico, pueden convertir en puramente ilusorio el inderogable derecho a impugnar la detención. Es por ello que el TEDH ha sido tajante en considerar dicha actitud contraria a la esencia del artículo 5.4 del CEDH, y ha recordado a los gobiernos la obligación de encontrar una solución intermedia a esta situación, que pasaría en su caso por el

\footnotetext{
${ }^{46}$ Vid asunto Sakik \& others $v$. Turquie, cit. supra, $\$ 53$.

47 Vid asunto $A \&$ Others $v$. The United Kingdom, cit. supra, $\$ 202$.
} 
nombramiento de un abogado especial, pero que en todo caso no puede atentar contra el núcleo duro de tal derecho ${ }^{48}$.

\section{ASILO, DEVOLUCIÓN Y EXPULSIÓN EN SUPUESTOS DE TERRORISMO}

La relación entre el asilo y la lucha contra el terrorismo constituye, en el momento presente, el corazón de un vivo debate tras el comienzo de la nueva era de atentados terroristas. Así, algunos Estados en los que los implicados en ofensas terroristas estaban relacionados estrechamente bien con población descendiente de inmigrantes, refugiados o asilados, bien directamente con personas que en la actualidad disfrutan de esta protección, han insistido en su devolución a los países de origen o de residencia anterior, alegando su obligación de proteger a su población de la amenaza terrorista. Es cierto que el artículo 1 del CEDH, en combinación con los artículos 2 (derecho a la vida) y 3 (prohibición de tortura), impone de forma clara este deber. Sin embargo el TEDH ha dejado claro desde el principio, en general, que esta obligación ha de compatibilizarse en la práctica con otras obligaciones internacionales que emanan igualmente del Derecho Internacional de los Derechos Humanos ${ }^{49}$.

Por lo que hace a la lucha contra el terrorismo internacional en particular, el TEDH ha tenido ocasión de sostener que la obligación de no devolución no decae, pronunciándose al respecto en diferentes ocasiones, partiendo del principio de base de que las partes contratantes están obligadas a respetar este principio básico (non-refoulement). La expulsión de no nacionales, sospechosos de haber cometido en el pasado o poder cometer en el futuro actos terroristas, al margen del temor de éstos a ser maltratados o torturados en el país de destino, no es por tanto la respuesta correcta a este problema.

El TEDH ha recordado de forma insistente que la no expulsión o no devolución de una persona, incluso bajo sospecha de implicación en actividades terroristas, es un principio fundamental de la protección de los derechos humanos en Europa, ampliando el alcance tradicionalmente reconocido al principio de non-refoulement, limitado tan sólo al llamado Derecho internacional de los refugiados.

48 Vid asunto $A$ \& Others $v$. The United Kingdom, cit. supra, $\$ \$ 220-224$.

49 Vid asunto Salah Sheekh v. The Netherlands (Application n. ${ }^{\circ}$ 1948/04, de 23 mayo 2007), $\$ 135$; asunto Hilal v. The United Kingdom (Application n. $.^{\circ} 45276 / 99$, de 6 marzo 2001), \$ 59; asunto Müslim c. Turquie (Requête n. ${ }^{\circ}$ 53566/99, de 26 julio 2005), $\$ 66$. 
En concreto, en el caso del control de la población extranjera, el Tribunal ha recordado a los Estados que no pueden escapar de sus obligaciones convencionales para con la protección de los derechos fundamentales acogiéndose a la afirmación de que la regulación del derecho de extranjería es un atributo esencial de la soberanía estatal, utilizando dicho argumento como «carte blanche» para violar algunos principios básicos del Derecho internacional público y de la propia $\mathrm{CEDH}^{50}$, pues para el Estado que expulsa sigue existiendo la obligación de evitar que el extranjero expulsado pueda ser condenado a pena de muerte, sufrir penas o tratos crueles, inhumanos o degradantes, o ser torturado ${ }^{51}$. En esta línea, el TEDH no ha dudado en afirmar que, dado el carácter absoluto de la prohibición de la tortura o los tratos o penas crueles, inhumanos o degradantes, la naturaleza de las actividades desarrolladas por el individuo en cuestión es irrelevante por peligrosas o indeseables que éstas puedan ser, lo que concede mayor alcance a la protección ofrecida por el artículo 3 del CEDH que a la protección ofrecida por el artículo 33 del Convenio relativo al Estatuto de los refugiados ${ }^{52}$.

En este sentido, el Tribunal defendió la no expulsión de un nacional de la República Democrática del Congo que había pertenecido al círculo más íntimo de colaboradores del depuesto presidente Mobutu, incluso si había cometido ciertos ilícitos en Finlandia, por considerar que su expulsión lo pondría en situación de grave riesgo de torturas o tratos crueles, inhumanos o degradantes. $\mathrm{O}$ en el asunto Chahal v. The United Kingdom, y en relación directa con el tema que nos ocupa, la posible devolución de un solicitante de asilo por parte del Reino Unido a India, por la sospecha de su participación en actividades terroristas.

Partiendo de esta base, el TEDH ha dejado sentadas las bases de la aplicación estricta del principio de no devolución en el caso de cualquier persona detenida o internada, incluso si ésta puede estar relacionada con actividades terroristas, cuando dicha entrega pueda suponer su sometimiento a torturas o a tratos o penas crueles, inhumanos o degradantes, elevando consiguientemente el estándar de protección de dichas personas en comparación con el ofrecido por el Convenio de Ginebra de 1951. Y es que, si bien el TEDH no deja de reconocer que la $\mathrm{CEDH}$ no confiere ningún derecho a obtener asilo al particular, dejando

${ }^{50}$ Vid asunto N. v. Finland (Application n. ${ }^{\circ} 38885 / 02$, de 30 noviembre 2005), $₫ 158-159$.

51 Vid asunto Cruz Varas \& others v. Sweden (Application n. ${ }^{\circ}$ 15576/89, de 20 marzo 1991), $\$$ 69-70; asunto Vilvarajah \& others $v$. The United Kingdom (Applications n ${ }^{\text {os }}$ 13163/87; 13164/87; 13165/87; 13447/87; 133448/87, de 30 octubre 1991), \$\$ 102-103 y 107-108; asunto H.L.R. v. France (11/1996/630/813, de 29 abril 1997), $\$ 34$.

52 Vid asunto $N$. v. Finland, cit. supra, $\$ 159$. Y en lo que hace específicamente a la lucha contra el terrorismo, asunto Chahal v. The United Kingdom (Application n. ${ }^{\circ}$ 70/1995/576/662, de 15 de noviembre 1996), $\$ 79$. 
esta cuestión necesariamente en manos de los Estados, las partes contratantes podrían incurrir no obstante en violación del artículo 3 cuando la expulsión, deportación o devolución de la persona en cuestión la exponga al riesgo de las violaciones previstas en dicho artículo, interpretando, sensu contrario, dicha disposición como una obligación de los Estados partes de no deportar a esa persona a su país de origen o residencia ${ }^{53}$, huyendo de toda construcción artificiosa por parte de los Estados ${ }^{54}$.

A mayor abundamiento, el Tribunal ha rechazado en términos categóricos la argumentación rampante de algunas partes contratantes en el sentido de entender que la Convención obligaría a un balance entre el riesgo que potencialmente podría sufrir el particular deportado, expulsado o devuelto, y el peligro que su permanencia en el territorio nacional puede suponer ${ }^{55}$. Además, ha establecido que toda solicitud de asilo debe ser tratada individualmente y venir acompañada de la posibilidad de recurso de impugnación efectivo contra la decisión denegatoria en su caso. Ahora bien, en el supuesto de que el Estado de solicitud de asilo o de recepción del demandante de asilo disponga de elementos suficientes como para sospechar razonablemente de la implicación de éste en actividades terroristas, podrá rechazar dicha solicitud. Ello, sin embargo, no le releva de su obligación de asegurar que la devolución del demandante de asilo a su país de origen o a otro país no le expone a dicho riesgo. Además, el Tribunal ha recordado que el cumplimiento tanto de la orden de expulsión como de devolución debe ser llevado a cabo con el debido respeto a la integridad y dignidad de la persona afectada, evitando cualquier tipo de trato inhumano o degradante.

En definitiva la jurisprudencia del TEDH a este respecto, siendo consciente del deber de los Estados partes de proteger a la población de ataques terroristas,

53 Vid asunto Saadi v. Italy (Application n. ${ }^{\circ} 37201 / 06$, de 28 de febrero 2008), $₫ 125$.

${ }^{54}$ En concreto: «(...) The Court notes first of all that States face immense difficulties in modern times in protecting their communities from terrorist violence (...). It cannot therefore underestimate the scale of the danger of terrorism today and the threat it presents to the community. That must not, however, call into question the absolute nature of Article 3. (...) Since protection against the treatment prohibited by Article 3 is absolute, that provision imposes an obligation not to extradite or expel any person who, in the receiving country, would run the real risk of being subjected to such treatment. As the Court has repeatedly held, there can be no derogation from that rule (...) it is not possible to weight the risk of ill-treatment against the reasons put forward for the expulsion in order to determine whether the responsibility of a State is engaged under Article 3, even where such treatment is inflicted by another State. In that connection, the conduct of the person concerned, however undesirable or dangerous, cannot be taken into account, with the consequence that the protection afforded by Article 3 is broader that that provided for in Articles 32 and 33 of the 1951 United Nations Convention relating to the Status of Refugees (...)». Vid ibíd., \$\$137-138.

55 Vid ibíd., \$139. 
no hace sino recordar que la labor de combatir el riesgo de este tipo de ataques en relación con los no nacionales residentes en el propio territorio susceptibles de participar en tales actos no puede llevarse a la práctica, sino mediante métodos más elaborados que la simple expulsión o devolución, y que necesariamente pasan por mayores esfuerzos de integración, tolerancia y comprensión ${ }^{56}$.

De otra parte, puesto que la decisión de expulsión, deportación o devolución de una persona del territorio de un Estado conlleva su internamiento hasta la conclusión del procedimiento nacional pertinente, en lo que hace a la custodia de individuos sospechosos de actividad terrorista y su confinamiento en esta situación, la jurisprudencia aportada por el alto Tribunal deja claro que esta detención, en la medida en que priva de libertad al particular y puede someterle a condiciones en las que su seguridad pueda correr riesgo, debe reunir todos los requisitos exigidos a la detención por comisión o sospecha de comisión de un delito. En este sentido sólo la ha aceptado en tanto que el procedimiento de expulsión, deportación o extradición se completa, considerándola contraria al Convenio en caso de que la tramitación, a falta de la diligencia pertinente, alargue innecesariamente dicho internamiento ${ }^{57}$.

E igual que en los supuestos de detención la CEDH consagra el derecho a la revisión de la misma. Dado que el artículo 5 también contempla la protección frente al internamiento en espera de la culminación de un procedimiento de expulsión, deportación o devolución, el Convenio extiende igualmente esta garantía, vía artículo 13, a la decisión de expulsión. Esto se traduce en el ámbito de la lucha contra el terrorismo, donde el Estado intenta hacer valer limitaciones al disfrute de ciertos derechos fundamentales en aras de la protección de la seguridad nacional al margen de riesgos más o menos ciertos por parte de la persona afectada de sufrir torturas o malos tratos, en la afirmación tajante del TEDH de que, dada la naturaleza irreversible del daño que podría causarse y la prohibición absoluta que establece el artículo 3 del CEDH, el derecho a un recurso efectivo contemplado en el artículo 13 del $\mathrm{CEDH}$ requiere un escrutinio independiente, que debe realizarse sin tener en cuenta lo que la persona en cuestión haya podido hacer para merecer la expulsión o cualquier percepción de amenaza a la seguridad nacional del Estado que procede a la expulsión ${ }^{58}$.

56 En este sentido vid MOLE, N., Asylum and the European Convention of Human Rights Council of Europe Publishing, Strasbourg, 2008.

57 Vid asunto $A \&$ Others $v$. The United Kingdom, cit. supra, $\$ 164$, como ya lo había establecido, por otra parte, el TEDH en el asunto Chahal $v$. The United Kingdom, cit. supra, $\$ 113$. En el mismo sentido vid asunto Saadi v. Italy, cit supra, $\$ \$ 125-127$.

58 Vid asunto Chahal v. The United Kingdom, cit. supra, \$151. La afirmación es taxativa; no obstante, dada la insistencia por parte de los gobiernos, en los casos de intento de expulsión de in- 
Ello es lógico, si se tiene en cuenta que el TEDH establece una doble protección en relación al artículo 3 del $\mathrm{CEDH}$ : por un lado, la obligación de abstenerse de cualquier tipo de comportamiento o trato constitutivo de trato inhumano o degradante, en tanto que contenido sustantivo del propio artículo 3; y, por otro, la obligación de llevar a cabo en su caso una investigación adecuada y eficaz de los hechos acaecidos y denunciados como contrarios a dicho artículo o a su contenido procesal ${ }^{59}$, cuya inobservancia, además, pue-

dividuos como consecuencia de medidas de lucha antiterrorista, en primer lugar en no revelar ningún tipo de información que justifique dicha devolución como forma de protección del imperativo de seguridad nacional y, en segundo lugar, de privar a las personas afectadas de un recurso efectivo que permita revisar los motivos de fondo de la decisión, el Tribunal se ha visto obligado a ahondar en este planteamiento: "(...) In the present case, neither the advisory panel nor the courts could review the decision of the Home Secretary to deport Mr. Chahal to India with reference solely to the question of risk, leaving aside national security considerations. On the contrary, the Court's approach was one of satisfying themselves that the Home Secretary has balanced the risk to Mr. Chahal against the danger to national security (...) It follows from the above considerations that these cannot be considered effective remedies in respect of Mr. Chahal's Article 3 (art. 3) complaint for the purposes of Article 13 of the Convention (art. 13) (...)». Vid ibíd., $\$ 153$.

59 Vid asunto Dimitru Popescu c. Roumanie (N. ${ }^{\circ}$ 1) (Requête n. ${ }^{\circ}$ 49234/99, de 26 julio 2007), $\$ \$ 58$ y 70. En el mismo sentido vid asunto Lupascu c. Roumanie (Requête n. ${ }^{\circ} 14526 / 03$, de 4 noviembre 2008), $\$$ B; y, en particular, en supuestos concretos de terrorismo vid, entre otros, asunto Ilhan v. Turkey (Application n. ${ }^{\circ} 22277 / 93$, de 27 junio 2000), $\$ 89$.

El Tribunal ha establecido esa misma distinción en torno al contenido sustantivo o material, de un lado, y de otro lado procesal o formal del artículo 2 del CEDH relativo al derecho a la vida, que ha tenido ocasión de revisar en múltiples ocasiones respecto de actuaciones llevadas a cabo en el seno de los Estados contratantes en relación a personas implicadas o sospechosas de implicación en actividades terroristas y que han perdido la vida cuando se encontraban detenidas legal o ilegalmente por las fuerzas de seguridad del país correspondiente, o bien que han perdido la vida como consecuencia de un uso letal de la fuerza por parte de los cuerpos y fuerzas de seguridad del Estado en situaciones diversas (controles de carretera, manifestaciones, registros domiciliarios, etc.).

En cuanto al contenido procesal de dicho derecho, entendido como obligación positiva de hacer o impulsar (una investigación), frente a la obligación negativa o de no hacer (no matar intencionalmente), el Tribunal lo ha definido de la siguiente forma en el asunto Güleç: «(...) The procedural protection for the right to life in Article 2 of the Convention means that agents of the State must be accountable for their use of lethal force; their actions must be subjected to some form of independent and public scrutiny capable of determining whether the force used was or was not justified in a particular set of circumstances (...)». Vid asunto Güleç v. Turkey (54/1997/838/1044, de 27 julio 1998), $\$ 78$. En el mismo sentido vid asunto Çakici v. Turkey (Application n. ${ }^{\circ} 23657 / 94$, de 8 julio 1999), $\$ 86$.

Es más, el TEDH ha tenido ocasión de concretar dicho contenido en el asunto Finucane v. The United Kingdom: "(...) The essential purpose of such investigation is to secure the effective implementation of the domestic laws which protect the right to life and, in those cases involving State agents or bodies, to ensure their accountability for deaths occurring under their responsibility. What form 
de abrir en su caso al demandante la vía de recurso del artículo 13 del $\mathrm{CEDH}^{60}$.

En tal caso, y cuando la investigación pueda afectar a la violación de derechos fundamentales inderogables en cualesquiera circunstancias como son la prohibición de la tortura (artículo 3) o el derecho a la vida (artículo 2), el Tribunal ha aclarado la relación entre las dos obligaciones de investigar establecidas en los artículos 2 y 3 , de una parte, y en el artículo 13 de otra, dictaminando que el

of investigation will achieve those purposes may vary in different circumstances. However, whatever mode is employed, the authorities must act of their own motion, once the matter has come to their attention. They cannot leave it to the initiative of the next-of-kin either to lodge a formal complaint or to take responsibility for the conduct of any investigative procedures. For an investigation into alleged unlawful killing by State agents to be effective, it may generally be regarded as necessary for the persons responsible for and carrying out the investigation to be independent from those implicated in the events (...) This means not only a lack of hierarchical or institutional connection but also a practical independence (...) The investigation must also be effective in the sense that it is capable of leading to a determination of whether the force used was or was not justified in the circumstances (...) and to the identification and punishment of those responsible (...) This is not an obligation of result, but of means. The authorities must have taken the reasonable steps available to them to secure the evidence concerning the incident, including, inter alia, eyewitness testimony, forensic evidence and, where appropriate, an autopsy which provides a complete and accurate record of injury and an objective analysis of clinical findings, including the cause of death (...) Any deficiency in the investigation which undermines its ability to establish the cause of death or the person or persons responsible will risk falling foul of this standard (...) A requirement of promptness and reasonable expedition is implicit in this context (...) While there may be obstacles or difficulties which prevent progress in an investigation in a particular situation, a prompt response by the authorities in investigating a use of lethal force may generally be regarded as essential in maintaining public confidence in their adherence to the rule of law and in preventing any appearance of collusion in or tolerance of unlawful acts (...) For the same reasons, there must be a sufficient element of public scrutiny of the investigation or its results to secure accountability in practice as well as in theory. The degree of public scrutiny required may well vary from case to case. In all cases, however, the next-of-kin of the victim must be involved in the procedure to the extent necessary to safeguard his or her legitimate interests (...)" (vid asunto Finucane v. The United Kingdom (Application n. ${ }^{\circ}$ 29178/95, de 1 octubre 2003), $\$ \$$ 67-71). En este mismo sentido vid asuntos Hugh Jordan v. The United Kingdom (Application n. ${ }^{\circ} 24746 / 94$, de 4 mayo 2001); asunto Gül v. Turkey (Application n. ${ }^{\circ}$ 22676/93, de 14 diciembre 2000), \$\$ 76-95; asunto Mahmut Kaya v. Turkey (Application n. ${ }^{\circ} 22535 / 93$, de 28 marzo 2000), \$\$ 95-108; asunto McCann \& others v. The United Kingdom (17/1994/464/545, de 27 septiembre 1995); asunto Tanrikulu v. Turkey (Application n. ${ }^{\circ} 23763 / 94$, de 8 julio 1999), \$\$ 105-111; asunto Tepe v. Turkey (Application n. ${ }^{\circ}$ 27244/95, de 9 mayo 2003), $\$ \$ 174-182$; asunto Yasa v. Turkey (63/1997/847/1054, de 2 septiembre 1998), \$\$ 98-108; asunto Berktay c. Turquie (Requête n. ${ }^{\circ}$ 22493/93, de 1 junio 2001); asunto Ogur v. Turkey (Application n. ${ }^{\circ}$ 21594/93, de 20 mayo 1999), $\$ \$ 78-84$; asunto McKerr v. The United Kingdom (Application n. ${ }^{\circ} 28883 / 95$, de 4 agosto 2001$), \$ \$ 108-115$ y $\$ \$ 157-161$.

${ }^{60}$ Vid asunto Chahal v. The United Kingdom, cit. supra, $\$ 154$.

(C) UNED. Revista de Derecho Político

N. ${ }^{\circ} 79$, septiembre-diciembre 2010, págs. 285-333 
«remedio» o recurso previsto en el artículo 13 debe ser efectivo tanto en la práctica como desde el punto de vista legal, especialmente en el sentido de que su ejercicio no debe verse injustificadamente impedido por actos u omisiones de las autoridades del Estado demandado. No obstante, dada la importancia esencial del derecho a la protección de la vida, el artículo $13 \mathrm{CEDH}$ requeriría, además del pago de una compensación en su caso, también una investigación efectiva y en profundidad, accesible al afectado, capaz de identificar y sancionar a los responsables de la privación de libertad en causa ${ }^{61}$.

De hecho, esta valoración, a la hora del respeto del artículo 2 del CEDH, de dos aspectos inherentes al derecho a la vida o a la prohibición de las torturas ha permitido en numerosas ocasiones al Tribunal condenar a un Estado por desapariciones, muertes o torturas a personas opuestas al régimen político en donde, en virtud de las técnicas empleadas por las fuerzas militares, para-militares o policiales del Estado denunciado, era muy difícil establecer la certidumbre de los hechos denunciados por los afectados, habida cuenta además del papel subsidiario del TEDH respecto de los tribunales nacionales, primeros encargados de establecer los hechos de cada caso ${ }^{62}$.

Por otro lado y en relación directa con demandantes potencial o realmente implicados en actividades terroristas o involucrados en episodios relacionados con la lucha contra el terrorismo, como por ejemplo en el caso de Turquía respecto de los individuos considerados como simpatizantes del PKK, el Tribunal no ha dudado en afirmar que el artículo 2 del CEDH no sólo prohíbe la muerte intencional, sino también los supuestos de muerte acaecida como consecuencia de un uso no prohibido de la fuerza pero sí excesivo o incontrolado, subrayando que toda fuerza que no sea estrictamente necesaria para satisfacer los apartados a) a c) del artículo 2 del CEDH violaría dicho derecho. Y a los efectos de valorar una situación semejante el TEDH no ha dudado en aplicar

${ }^{61}$ Vid asunto Mahmut Kaya v. Turkey, cit. supra, $\$ \$ 124-126$. En el mismo sentido vid asunto Çakici v. Turkey, cit. supra, $\$ 113$.

${ }^{62}$ Ello ha sido especialmente notorio en numerosos casos contra Turquía respecto de individuos simpatizantes del PKK, o en décadas anteriores respecto de la actuación de dichos cuerpos en el Reino Unido en relación a miembros del IRA. El Tribunal ha venido a reconocer este efecto en términos más difusos, al afirmar en el asunto Ilhan $v$. Turkey, respecto del contenido procesal del artículo 2 - pero aplicable igualmente al artículo 3 del CEDH- que: «(...) Procedural obligations have been implied in varying contexts under the Convention, where this has been perceived as necessary to ensure that the rights guaranteed under the Convention are not theoretical or illusory but practical and effective. The obligation to provide an effective investigation into the death caused by, inter alios, the security forces of the State was for this reason implied under Article 2 which guarantees the right to life (...)».Vid asunto Ilhan $v$. Turkey, cit. supra, $\$ 91$. 
los controles más severos y el balance más estricto, más allá de un mero test de necesidad ${ }^{63}$.

Pero además, la posible expulsión, deportación o devolución del solicitante de asilo a su país de origen ha puesto sobre la mesa el problema de la compatibilidad con el Convenio de las llamadas garantías o seguridades de trato compatible ofrecidas por parte del Estado receptor hacia la persona entregada. Puesto que, como acaba de verse, dicha expulsión, deportación o devolución del solicitante de asilo puede plantear incompatibilidad con el Convenio en la medida en que la persona afectada pueda verse sometida a una conducta contraria a los derechos consagrados en los artículos 2 ó 3 del CEDH, los Estados partes que se encuentran en la situación de devolver a la persona en cuestión han intentado salvar el escollo de verse obligados a mantener en su territorio a una persona considerada como non grata obteniendo del Estado receptor correspondiente garantías o seguridades formales de no aplicar un trato contrario al $\mathrm{CEDH}$, o lo que es lo mismo, las conocidas como "garantías diplomáticas», por las que el Estado receptor se comprometería a respetar en la persona devuelta, deportada o expulsada los derechos fundamentales contemplados en el $\mathrm{CEDH}$, en especial la prohibición de torturas o tratos o penas crueles, inhumanos o degradantes y el derecho a la vida.

En estos supuestos, el punto general de partida del Tribunal es siempre el mismo: no entra dentro de su competencia examinar las demandas de asilo o de controlar la forma en la que los Estados cumplen con las obligaciones impuestas por el Convenio de 1951, sino que su preocupación esencial es saber si, en la consideración de la solicitud de asilo, se aplican las necesarias garantías procesales de forma efectiva, sean éstas del tipo que sean siempre que protejan al solicitante contra una devolución arbitraria ${ }^{64}$.

La forma en que los Estados receptores prestan estas garantías varía de un supuesto a otro ${ }^{65}$. Sin embargo, la precaución y el nivel de compromiso material y no meramente formal que el Tribunal exige es considerable, advirtiendo en

${ }^{63}$ Vid asunto Gül v. Turkey, cit. supra, $\$ 77$. En el mismo sentido vid asunto McCann \& others $v$. The United Kingdom, cit. supra, $\$ \$ 148-149$; y el asunto Ilhan v. Turkey (Application n. ${ }^{\circ}$ 22277/93, de 27 junio 2000), \$74.

${ }^{64}$ Vid, entre otros, asunto Müslim c. Turquie, cit. supra, $\$ 72$.

${ }_{65}$ Pese a la escasa documentación al respecto, vid Group of Specialists on Human Rights and the Fight against Terrorism, Final Activity Report of the DH-S-TER on Diplomatic Assurances, Doc. CM (2006) 64, de 13 abril 2006; Compilation of the replies to the questionnaire on the practice of States in the use of diplomatic assurances, DH-S-TER, 2006 (002); y SÁNCHEZ LEGIDO, A.: "Garantías diplomáticas, no devolución y prohibición de la tortura», LX REDI (2008-1), pp. 11-38. 
muchos casos de la existencia del riesgo real de torturas o persecución y, por tanto, de violación del Convenio por parte del Estado que entrega. En cuanto a los factores que el TEDH toma en cuenta de forma sistemática a la hora de valorar dicho riesgo se encuentra la inevitable apreciación de la situación en el país de destino ${ }^{66}$; las alegaciones de las partes, demandante y Estado demandado; o los informes existentes — si los hubiera - de OIGs y ONGs para valorar el contexto general del país ${ }^{67}$. En este sentido, el Tribunal ha aclarado que en el supuesto de una devolución aún no materializada, el riesgo debe ser evaluado respecto de la situación del país de destino en el momento en el que el Tribunal conoce de la demanda, pese a que el estudio histórico del conflicto o de la situación en cuestión pueda arrojar luz sobre esa valoración, pero no altera el momento en que ésta debe ser realizada ${ }^{68}$.

Y aunque el Tribunal puede decidir no sólo con base en los materiales, informes y orientaciones aportados por las partes, sino también de todas aquellas informaciones recabadas por sí mismo, el elemento determinante será en todo caso los efectos específicos que sobre el demandante, habida cuenta de sus circunstancias personales, pueden tener los hechos estudiados, como puso claramente de manifiesto en el asunto Saadi v. Italy ${ }^{69}$. Por eso, pese a reconocer la buena fe que puede presidir muchas de las garantías ofrecidas por el Estado de destino, el TEDH ha optado por afirmar que existe violación del CEDH en caso de entrega del demandante ${ }^{70}$. Pero sobre todo ha permanecido firme e impasible, sosteniendo esta misma jurisprudencia en tiempos de "guerra» contra el terro-

${ }^{66}$ Vid asunto Müslim c. Turquie, cit. supra, $\$ 66$.

67 Por ejemplo, en el asunto Salah Sheekh $v$. The Netherlands, y ante el riesgo de ser torturado al ser devuelto a Somalia por pertenencia a una determinada etnia, el TEDH tuvo especialmente en cuenta el informe de UNHCR que sostenía, frente a las garantías ofrecidas por el gobierno, la probabilidad de torturas a personas pertenecientes a ciertas etnias en caso de ser devueltas a determinadas zonas del país diferentes de las señaladas como inestables por el gobierno somalí (vid asunto Salah Sheekh v. The Netherlands, cit. supra, $\$ 143$ ). O en el asunto Müslim c. Turquie, en el que se plantea la devolución del demandante a Irak y se da especial peso al plan de repatriación iniciado por UN y apoyado por el Consejo de Europa para denegar la posible violación del artículo 3 del CEDH, afirmando el Tribunal además: «(...) Vu ses constatations précédentes et n'ayant aucun motif de douter de ce que le gouvernement défendeur se conformera à ses engagements internationaux, la Cour conclut à l'absence de motifs sérieux et avérés de croire que l'expulsion éventuelle du requérant exposerait celui-ci à un risque réel de subir des traitements dépassant le seuil minimum fixé par l'article 3 (...)» (vid asunto Müslim c. Turquie, cit. supra, \$75). Igual importancia tuvieron en el asunto Saadi v. Italy los informes facilitados por Amnesty International y Human Rights Watch (vid asunto Saadi v. Italy, cit. supra, $\$ 143$ ).

${ }^{68}$ Vid asunto Chahal v. The United Kingdom, cit. supra, $\$ 86$.

${ }^{69}$ Vid asunto Saadi v. Italy, cit. supra, $\$ 143$.

70 Vid ibíd., \$105. 
rismo, ante los intentos por parte de los Estados partes de rebajar esta protección ${ }^{71}$. Por otra parte, más allá de lo "políticamente correcto», el TEDH no ha dudado en acusar veladamente a los Estados partes de cierta permisividad en la materialización de dichos riesgos, y no se ha conformado con garantías forma$\operatorname{les}^{72}$. Incluso cabría añadir, como ya lo afirmó abiertamente el TEDH en el caso de utilización de la cláusula derogatoria del artículo 15 del CEDH, que el valor de estas garantías queda sujeto a su control de compatibilidad con el Convenio.

\section{TERRORISMO Y DETENCIÓN A LOS EFECTOS DE EXTRADICIÓN}

El artículo 5.1, f) del CEDH permite la detención de un individuo, a los efectos de su extradición, cuando haya sido requerido por otro Estado. En este sentido este apartado se diferencia del apartado c) del mismo artículo, como el propio Tribunal ha tenido ocasión de aclarar, en que ya no se trata de valorar la razonabilidad de la necesidad de detener a una persona para prevenir la comisión de un delito o para impedir su fuga una vez cometido. Puesto que la solicitud de extradición contiene su propia justificación y que el CEDH no se pronuncia en materia de extradición, no es necesario en estos supuestos valorar la justificación de la detención en la medida en que la orden de extradición se haya producido, pero sí el procedimiento conforme al cual se detiene a la persona requerida ${ }^{73}$.

Lo decisivo en este caso es que la petición de extradición existe y se procede a la detención de la persona requerida a los efectos de su entrega al Estado requirente mediante el procedimiento establecido internamente por ley y con las suficientes garantías legales, que deben estar regladas en el Estado de detención $^{74}$. El Tribunal entra por tanto a valorar si el procedimiento previsto en el sis-

71 En este sentido ha afirmado: «(...) Lastly, the United Kingdom Government emphasised that Contracting States Could obtain diplomatic assurances that an applicant would not be subjected to treatment contrary to the Convention. Although, in the above-mentioned Chahal case, the Court had considered it necessary to examine whether such assurances provided sufficient protection, it was probable, as had been shown by the opinions of the majority and the minority of the Court in that case, that identical assurances could be interpreted differently (...)». Vid ibíd., \$123.

72 Vid ibíd., \$\$ 147-148.

${ }^{73}$ Vid asunto Ismoilov \& others v. Russia (Application n. ${ }^{\circ}$ 2947/06, de 1 diciembre 2008), $\$ 135$; asunto Soldatenko v. Ukranie (Application n. ${ }^{\circ}$ 2440/07, de 23 enero 2009), cit. supra, $\$ 109$. En el mismo sentido vid asuntos Conka v. Belgium, cit. supra, $\$ 38$; Chahal v. The United Kingdom, cit. supra, $\$ 112$.

${ }^{74}$ En todo caso el Tribunal se ha mostrado antiformalista respecto del procedimiento de extradición en sí mismo, y preocupado tan sólo por controlar los elementos de fondo y no tanto de 
tema jurídico interno de que se trate está en conformidad con las obligaciones asumidas en el $\mathrm{CEDH}$, incluyendo los principios generales expresamente o implícitamente contenidos en el Convenio. A este respecto ha aclarado que "conforme a derecho" no significa tan sólo de acuerdo con el procedimiento establecido por ley, sino que además hace referencia a la "calidad» de dicha ley interna $^{75}$. En este sentido ha entendido que no lo es una ley interna en cuyo procedimiento de extradición no queden establecidas las condiciones de la posible detención con vistas a aquella; esto es, el procedimiento de orden y ejecución de una petición de extradición, los límites temporales de esa posible detención, así como una serie de salvaguardas mínimas a favor del detenido que le protejan de toda arbitrariedad ${ }^{76}$.

E igualmente le es de aplicación a esta detención la garantía prevista en el apartado segundo del artículo 5: la persona detenida con vista a su entrega mediante un proceso de extradición debe ser informada suficientemente y en breve plazo de las razones de su detención, o al menos obtener una información genérica mínima que le permita deducir fácilmente que se encuentra afectada por un proceso semejante ${ }^{77}$, así como el derecho a disponer de un recurso para impugnar la decisión de extradición ante alguna instancia nacional ${ }^{78}$ y a contar con el asesoramiento de un abogado para ello ${ }^{79}$.

forma de ese procedimiento, en especial en lo que hace a las garantías del artículo 5 del CEDH: «(...) La Convention ne contient pas de dispositions sur les conditions dans lesquelles une extradition put être accordée, ni sur la procédure à appliquer avant même que l'extradition ne puisse être accordée. Même une extradition atypique, sous réserve qu'elle soit issue d'une coopération entre les Etats concernés et que l'ordre d'arrestation trouve sa base légale dans un mandat d'amener décerné par les autorités de l'Etat d'origine de l'intéressé, ne saurait être, en tant que telle, contraire à la Convention (...)». Vid asunto Soysal c. Turquie, cit. supra, $\$ 59$.

75 Vid asunto Nasrulloyev v. Russia (Application n. ${ }^{\circ}$ 656/06, de 11 enero 2008), $\$ 71$; asunto Ismoilov \& others v. Russia, cit. supra, $\$ \$ 137-138$; asunto Soldatenko v. Ukranie, cit. supra, $\$ 111$.

${ }^{76}$ El Tribunal ha añadido, así mismo, que la decisión adoptada por parte de las autoridades competentes del Estado contratante en cuyo poder se encuentre la persona sujeta al procedimiento de extradición, por la cual se acepta la entrega de dicha persona, no puede violar la presunción de inocencia, e.g. dando por sentado en su texto de la forma que sea que los hechos de que se le acusan por parte del Estado requirente se han cometido efectivamente antes de ser sometido al correspondiente proceso judicial en el Estado requirente (vid asunto Ismoilov \& others $v$. Russia, cit. supra, $\$ \$ 166-170)$.

77 Vid asunto Chamaïev et autres c. Géorgie et Russie (Requête n. ${ }^{\circ}$ 36378/02, de 12 octubre 2005), $\$ \$ 414$ y 425-426; asunto Soysal c. Turquie, cit. supra, $\$ 68$.

${ }_{78}$ Vid asunto Chamaïev et autres c. Géorgie et Russie, cit. supra, $\$ 443$; asunto Ismoilov \& others $v$. Russia, cit. supra, $\$ 152$.

79 Vid asunto Soysal c. Turquie, cit. supra, $\$ \$ 77-80$. 
De la misma forma que la CEDH no se pronuncia sobre el derecho al asilo de una persona bajo la jurisdicción de una parte contratante, nada dice acerca de la extradición que implica en definitiva la salida del territorio de una parte contratante de una persona bajo su jurisdicción, que es entregada a otro Estado, ser parte contratante o no. Sin embargo, la extradición es un procedimiento esencial para una cooperación internacional efectiva en la lucha contra la delincuencia en general, y contra el terrorismo en particular, como ha tenido ocasión de recordar el Tribunal ${ }^{80}$. Ello no ha impedido, no obstante, que el Tribunal corrija las apreciaciones excesivamente generosas de los Estados contratantes en relación a esta cooperación ${ }^{81}$.

De hecho, la extradición ha constituido la pieza clave desde la que se ha construido todo el mecanismo convencional de cooperación en la lucha contra el terrorismo internacional en el seno del Consejo de Europa ${ }^{82}$, en otros ámbitos regionales, e incluso en el plano universal ${ }^{83}$. Como consecuencia de la compe-

${ }^{80}$ Vid ibíd., $\$$ 60; asunto Öcalan v. Turkey (Application n. ${ }^{\circ} 46221 / 99$ ), cit. supra, $\$ \$ 87-90$; asunto Soldatenko v. Ukranie, cit. supra, $\$ 80$.

${ }^{81}$ Conforme a las propias palabras de Tribunal: «(...) The Court is not convinced by the Government' argument that they had an obligation under international law to cooperate in fighting terrorism and had a duty to extradite the applicants who were accused of terrorist activities, irrespective of a threat of ill-treatment in the receiving country. It is not necessary for the Court to enter into a consideration of the Government's untested allegations about the applicants' terrorist activities because they are not relevant for its analysis under Article 3. The Court is well aware of the immense difficulties faced by States in modern times in protecting their communities from terrorist violence. However, even in these circumstances, the Convention prohibits in absolute terms torture or inhuman or degrading treatment or punishment, irrespective of the victim's conduct. The probibition provided by Article 3 against ill-treatment is equally absolute in expulsion and extradition cases. Thus, whenever substantial grounds have been shown for believing that an individual would face a real risk of being subjected to treatment contrary to Article 3 if removed to another State, the responsibility of the Contracting State to safeguard him or her against such treatment is engaged in the event of expulsion or extradition. In these circumstances, the activities of the individual in question, however undesirable or dangerous, cannot be a material consideration (...)». Vid asunto Ismoilov \& others v. Russia, cit. supra, $\$ 126$.

${ }^{82}$ Vid artículo 1 del Convenio para la Supresión del Terrorismo, CETS n. ${ }^{\circ}$ 90; artículo 3 de Protocolo de enmienda al anterior CETS n. ${ }^{\circ} 190$, artículos 17 y 18 del Convenio para la Prevención del Terrorismo, entre otros.

${ }^{83}$ Vid, por ejemplo, el artículo 8.1 del Convenio para la represión del apoderamiento ilícito de aeronaves, de 16 de diciembre de 1970 (Convenio de La Haya); el artículo 8.1 del Convenio para la represión de actos ilícitos contra la seguridad de la aviación civil, de 23 de septiembre de 1971 (Convenio de Montreal); ídem del Convenio para la prevención y sanción de los delitos cometidos contra personas internacionalmente protegidas, de14 de diciembre de 1973; el artículo 10.1 del Convención internacional contra la toma de rehenes, de 17 de diciembre de 1979; el artículo 11.1 del Convenio de Roma; el artículo 9.1 del Convenio para la represión de los atentados terroristas cometidos con bombas; el artículo 11 del Convenio para la represión de la financiación del terrorismo; o el artículo 13 del Convenio para la represión de los actos de terrorismo nuclear. 
tencia del TEDH para valorar la interpretación y aplicación de este concreto precepto hecha por las partes contratantes con el Convenio, se han traído ante dicha instancia jurisdiccional una serie de casos en los que se planteaba la compatibilidad de una posible extradición con el disfrute de algunos de los derechos protegidos en el Convenio, en especial su artículo 3.

En el asunto Soering $v$. The United Kingdom, el demandante planteaba ante el TEDH por primera vez que su extradición desde el Reino Unido a los Estados Unidos de América para afrontar un juicio con pena capital supondría la violación, por parte de un Estado parte, del artículo 3 del CEDH, desde el momento de que el cumplimiento de la sentencia de muerte que pesaría sobre él le obligaría a permanecer una serie de años en el conocido como "corredor de la muerte» esperando su ejecución, lo que constituiría bien tortura, bien trato cruel o inhumano, un planteamiento que finalmente el Tribunal admitió ${ }^{84}$.

Este importante principio fue generalizado después por la propia jurisprudencia del Tribunal, a todo proceso de salida de un extranjero del territorio nacional de una parte contratante hacia otro Estado en el que exista un riesgo real de trato incompatible con las obligaciones establecidas en el artículo 3 del $\mathrm{CEDH}$. Además, la obligación de no devolver a una persona se extiende cuando ésta pueda demostrar que dicho peligro procede de la falta de voluntad de las autoridades estatales de protegerle frente a posibles malos tratos o torturas por parte de actores no estatales ${ }^{85}$. Ello pone de nuevo de manifiesto que la $\mathrm{CEDH}$ ofrecería, también en este aspecto, una mayor protección del principio de no devolución que el propio Convenio de Ginebra sobre el estatuto de los refugiados, dado que el carácter absoluto que alcanza la prohibición de los tratos crueles inhumanos o la tortura en el sistema convencional del Consejo de Europa impe-

${ }^{84}$ Vid asunto Soering $v$. The United Kingdom (Application n. ${ }^{\circ}$ 14038/88, de 7 julio 1989). Especialmente interesante a este respecto resulta el supuesto de entrega, como consecuencia del abandono de la administración de un territorio ocupado, a las nuevas autoridades judiciales de dicho territorio de las personas detenidas por el Estado ocupante, en el caso de que éstas puedan quedar sometidas a la pena de muerte, acarreando por tanto la posible responsabilidad internacional de la parte contratante que procede a dicha entrega en caso de violación del derecho a la vida, y de la prohibición de los tratos o penas crueles, inhumanos o degradantes. Vid al respecto el asunto Al-Saadoon and Mufdhi v. The United Kingdom (Application n. ${ }^{\circ}$ 61498/08, de 2 marzo 2010).

${ }^{85}$ A este respecto resulta clarificadora la afirmación del Tribunal en el asunto $N$. v. Finland: "(...) The Court would add that the risk of ill-treatment to which the applicant would be exposed if returned to the DRC at this moment in time might not necessarily emanate from the current authorities but from relatives of dissidents who may seek revenge on the applicant for his past activities in the service of President Mobutu (...)", o lo que es lo mismo, por parte de actores no estatales (vid asunto N. v. Finland, cit supra, $\$ 163)$. 
diría a un Estado contratante no ya devolver a una persona, tal y como esto se entiende en el marco del derecho internacional de los refugiados, o deportarla en tanto que extranjero irregular o non grato como se ha visto, sino también entregarla a otro Estado por medio del mecanismo de la extradición, sea cual fuere la amenaza que ésta constituya, incluso para los más altos intereses nacionales. Y ello porque sería difícilmente compatible con la herencia común de tradiciones políticas, ideales, libertad y el Estado de derecho, invocados en el preámbulo del Convenio, que un Estado contratante devolviese a una persona a sabiendas de la existencia de serio riesgo de torturas o tratos crueles, inhumanos o degradantes ${ }^{86}$.

Igualmente, cuando el argumento esgrimido por la persona requerida en extradición concierne a una efectiva o potencial denegación absoluta de justicia por parte del Estado requirente, el Estado requerido tiene la obligación de contrastar el fundamento de dicho argumento antes de decidir sobre la concesión de la extradición $^{87}$.

Además de los asuntos analizados hasta aquí, un segundo conjunto de elementos se plantean en relación con la extradición y la lucha contra el terrorismo con renovado interés. A este respecto, el punto de partida viene dado por las directrices establecidas por la jurisprudencia del Tribunal cuando el límite al derecho a la libertad de un detenido por actividades terroristas se produce en conexión con un proceso de extradición: el Tribunal valorará el riesgo de violación del artículo $3 \mathrm{CEDH}$ teniendo en cuenta los hechos e informaciones alegados por las partes, pero también los obtenidos motu proprio, prestando especial atención a la situación general del país, las circunstancias personales de la persona afectada por el proceso de extradición, y concediendo respecto de esta valoración la debida importancia a los informes recientes que se puedan haber producido en el seno de asociaciones internacionales independientes pro derechos humanos o de fuentes gubernamentales ${ }^{88}$.

No por ello el Tribunal ignora las competencias de los Estados en materia de control de extranjeros, ni las dificultades que la lucha contra el terrorismo im-

${ }^{86}$ Ya apuntado en términos generales en el asunto Soering $v$. The United Kingdom, cit. supra, pero perfectamente delimitado en relación con el Estado de Derecho y los principios democráticos en el asunto Mamatkulov and Askarov v. Turkey (Application n. ${ }^{\circ} 46827 / 99$, de 4 febrero 2005), en especial vid $₫ 68$.

${ }^{87}$ Establecido en términos generales con anterioridad en los asuntos Soering $v$. The United Kingdom y Drozd and Janousek v. France and Spain (Application n. ${ }^{\circ} 12747 / 87$, de 26 de junio 1998), pero en particular en relación con el terrorismo en el asunto Mamatkulov and Askarov v. Turkey, cit. supra, $\$ \$ 90-91$.

${ }_{88}$ Vid asunto Soldatenko v. Ukraine, cit. supra, $\$ \$ 66-67$, y asunto Kaboulov v. Ukraine (Application n. ${ }^{\circ} 41015 / 04$, de 19 noviembre 2009), $\$ 107$. 
plica. Ahora bien, considera que estas circunstancias no pueden justificar la entrega, mediante un proceso de extradición, de una persona que pueda verse sometida, como consecuencia de la misma, a un trato contrario al artículo 3 del $\mathrm{CEDH}^{89}$.

En todo caso es cierto que, si bien el Estado en cuestión está obligado a no entregar en caso de tal riesgo a una persona sospechosa de implicación en actividades terroristas, incluso a pesar de ser requerido a tal fin, puede encontrarse en la difícil situación de tener que mantener por largo tiempo en su territorio a una persona sospechosa de actividades terroristas a la que no puede expulsar o devolver, pero a la que tampoco puede detener, a pesar de que la considere como un peligro grave para la seguridad nacional. $\mathrm{O}$ bien permitir que tal persona pueda salir hacia el territorio de otro Estado en el que no corra el riesgo, en principio, de sufrir un tratamiento contrario al artículo 3 del CEDH, pero en el que, sin embargo, pueda retomar actividades terroristas, como los recientes acontecimientos en relación con ciertos presos yemeníes, detenidos en la prisión de Guantánamo, han puesto de manifiesto.

En el referido asunto Soering el TEDH estableció la posibilidad de entregar en extradición a una persona que, requerida a una parte contratante, temía ser víctima de trato contrario al artículo 3 del $\mathrm{CEDH}$, siempre que el Estado requirente ofreciese suficientes garantías de respeto de las citadas obligaciones. El deseo de los Estados en general, y de las partes contratantes al CEDH en particular, por poner fuera de sus fronteras a toda persona susceptible de constituir una amenaza terrorista o relacionada de cualquier forma con el terrorismo, les ha movido a plantear la devolución de éstas cuando se encontrasen ilegalmente en su territorio, la denegación de la solicitud de asilo, o la extradición cuando fuesen requeridas por terceros Estados. Y en el caso del terrorismo integrista en particular, la tendencia de los Estados a entregar a dichos individuos, previa recepción de las conocidas como "garantías diplomáticas» por parte de los Estados requirentes —en muchos casos más de carácter formal que material-, ha puesto sobre la mesa la adecuación de dichas garantías a la protección de los derechos amparados por el CEDH. El estudio de dicha figura, invocada con insistencia por los Estados involucrados en la llamada "guerra contra el terrorismo" a la que hemos tenido ocasión de referirnos al estudiar el asilo, excede el planteamiento de este estudio, sin embargo, resulta pertinente en todo caso recordar la posición del TEDH respecto de dichas garantías cuando ha debido apreciar su compatibilidad con el disfrute de algunos de los derechos reconocidos en la Convención ante una acción por parte de un Estado contratante encuadrada en la lucha con-

${ }^{89}$ Vid asunto Chamaïev et autres c. Géorgie et Russie, cit. supra, $\$ \$ 334-335$. 
tra el terrorismo. En este sentido el Tribunal ha afirmado ante todo que el control realizado lo es en relación tan sólo con el respeto por parte del Estado contratante de los derechos protegidos por el CEDH en la persona del demandante, pero que en ningún caso implica valoración o condena alguna respecto del Estado hacia el que se pretende extraditar al demandante ${ }^{90}$.

$\mathrm{Y}$ en lo que hace al momento en que dicho análisis debe realizarse, el TEDH ha recibido demandas en dos situaciones diferentes: cuando la extradición está pendiente de la decisión del Tribunal, incluso con la adopción por parte de éste de medidas provisionales, o cuando finalmente la extradición ya se ha producido. En el primer caso, esto es, cuando la extradición no se ha producido y, por tanto, la persona no ha sido aún entregada en el momento en el que el TEDH es requerido para pronunciarse, la valoración de los acontecimientos sobre los que se funda el temor a ser tratado de forma contraria al artículo 3 del CEDH debe hacerse en relación al momento en el que el Tribunal está conociendo de la causa.

Por el contrario, cuando la extradición ya se ha producido, el Tribunal debe proceder a dicha valoración sobre la base de los hechos que eran conocidos por parte de la Parte contratante que procedió a la extradición en el momento de producirse ésta, o que debían haber sido conocidos en tal momento por dicha Parte, aunque en este caso el TEDH se deje a sí mismo abierta la puerta para tomar también en consideración, dado el tiempo que puede haber transcurrido entre ambos momentos, información pertinente que haya podido producirse $a$ posteriori hasta el momento de decidir sobre la demanda ${ }^{91}$.

Y en relación a las garantías diplomáticas, éstas no sólo deben prestarse lógicamente con carácter previo y como condición a la entrega de la persona concernida, sino que además deben prestarse, en primer lugar, por el órgano nacional competente para asumir válidamente dichos compromisos por parte del Estado requirente ya que de lo contrario no serán consideradas como válidas ${ }^{92}$;

${ }^{90}$ Vid ibíd, $\$ 337$.

91 Vid asunto Mamatkulov and Askarov v. Turkey, cit. supra, $\$ 69$, y asunto Chamaïev et autres c. Géorgie et Russie, cit. supra, $\$ 337$, en materia de terrorismo, aunque dicha aproximación ya había sido avanzada en general en los asuntos Cruz Varas \& others v. Sweden, cit. supra, $\$ \$ 75-76$ y Vilvarajah \& others $v$. The United Kingdom, cit. supra, $\$ 107$.

${ }_{92} \mathrm{Tal}$ y como el TEDH tuvo ocasión de afirmar en el asunto Chamaïev et autres c. Géorgie et Russie, cit. supra, al afirmar que: «(...) Appréciant la crédibilité que les autorités géorgienes ont pu attribuer à ces garanties, la Cour juge important le fait que celles-ci émanaient du procureur général, lequel dans le système russe contrôle les activités de l'ensemble des procureurs de la Fédération de Russie, qui soutiennent l'accusation devant les tribunaux (...). Il convient également de relever que les autorités du parquet remplissent un rôle de supervision du respect des droits des détenus dans la Fédération de 
y en segundo lugar, en términos suficientemente concretos en relación con el caso en cuestión, no habiendo considerado el Tribunal suficiente las garantías ofrecidas en términos genéricos ${ }^{93}$.

Por otro lado, la forma en que un Estado ejecuta una orden de extradición también puede constituir una violación del artículo 3 del CEDH, como por ejemplo el hecho de mantener encerrados en la misma celda a un elevado número de detenidos sometidos a una presión importante, ignorantes del desarrollo de ningún proceso de extradición en su contra, y la comunicación tan sólo unas horas antes y dentro de esta misma celda de que la entrega que culmina la orden de extradición se va a ejecutar de forma inminente, produciéndose en consecuencia una serie de altercados graves con los vigilantes de la prisión que conllevaron la aplicación de un tratamiento especialmente severo a los detenidos ${ }^{94}$.

En todo caso, el TEDH ha tenido ocasión de verificar hasta qué punto dichas garantías y seguridades pueden ser ineficaces pues, una vez prestadas con toda formalidad y en cumplimiento de todos los requisitos previstos, pueden ser olvidadas por los Estados una vez conseguida la extradición deseada, habiendo procedido en algún caso el Estado requirente a incumplir prácticamente todos los compromisos adquiridos ${ }^{95}$. No sólo eso, sino que el Tribunal ha podido comprobar de manera alarmante la persecución sistemática de personas de un determinado origen por parte de su Estado nacional en caso de que éstas hayan

\footnotetext{
Russie, ce rôle comprenant entre autres le droit de visite et de contrôle sans entraves dans les lieux de détention (...)» (vid asunto Chamaïev et autres c. Géorgie et Russie, cit. supra, $\$ 344$ ); o en el asunto Soldatenko v. Ukranie: "(...) The Court observes, however, that it is not at all established that the First Deputy Prosecutor General or the institution which he represented was empowered to provide such assurances on behalf of the State (...)» (vid asunto Sodatenko, cit. supra, $\$ 73$ ).

93 Como ha tenido ocasión de afirmarlo en Tribunal en el asunto Kaboulov v. Ukraine: "(...) As to whether the risks of the applicant have been excluded by assurances on the part of the Kazakhstan authorities, the Court recalls that the Kazakhstan General Prosecutor's Office informed the Ukrainian authorities (...) that the applicant would only be prosecuted for offences referred to in the extradition request, that is, murder, and (...) a further assurance was given that the applicant would not be liable to the death penalty (...). The Court notes that these assurances state generally that the applicant's rights and lawful interests in the course of criminal proceedings against him would be protected (...). They do not specifically exclude that the applicant would be subjected to treatment contrary to Article 3, and so cannot suffice to exclude the serious risks referred to above. The foregoing considerations, taken together, are sufficient to enable the Court to conclude that the applicant's extradition to Kazakhstan would be in violation of Article 3 of the Convention (...)». Vid asunto Kaboulov v. Ukraine, cit. supra, $\$ \$ 113-114$.

94 Vid ibíd. \$\$ 381-385.

95 Vid asunto Chamaïev et autres c. Géorgie et Russie, cit. supra, en especial $\$ \$ 362-362$; asunto Ismoilov \& others $v$. Russia, cit. supra, $\$ 113$.
} 
recurrido ante el propio $\mathrm{TEDH}^{96}$, todo lo cual le ha conducido a pronunciarse de forma tajante contra la aceptación de dichas garantías diplomáticas ${ }^{97}$.

\section{LA PROHIBICIÓN ABSOLUTA DE TORTURA O DE TRATOS O PENAS CRUELES, INHUMANOS O DEGRADANTES COMO PRINCIPIO GENERAL DE BASE DE TODA PRIVACIÓN DE LIBERTAD}

Como se ha podido constatar hasta ahora, el recuerdo de la prohibición de la tortura o de los tratos o penas crueles, inhumanos o degradantes en la jurisprudencia del TEDH relativa al artículo 5 del CEDH es constante, la mayoría de las veces pormenorizado y adecuado al aspecto concreto de la privación de libertad de que se trate, de ahí que haya sido necesario abordarlo en diferentes momentos a lo largo del desarrollo de este trabajo. Traerlo de nuevo a colación aquí podría resultar, pues, redundante. Sin embargo, desentrañar sus pilares, una vez analizados los detalles en relación con las medidas nacionales destinadas a combatir el terrorismo internacional, así como el tratamiento sustantivo, procesal y metodológico que el propio Tribunal le concede en el análisis de los diferentes casos no hace sino aquilatar una serie de líneas generales sobre las cuales se asienta, en definitiva, una prohibición general y absoluta de violación del artículo 3 del CEDH como sustrato de base en toda la protección que el artículo 5 —nuclear por otra parte en el diseño, planificación e implementación de la lucha contra el terrorismo internacional- ofrece en sus diversos apartados, más que como aportaciones concretas y expresas, como grandes conclusiones finales de base.

Por eso, para apreciar la importancia del principio en el conjunto de la construcción jurisprudencial del TEDH en materia del derecho a la libertad y a la seguridad cuando de terrorismo se trata, tal vez haya que recordar el valor

96 Vid ibíd., $\$ 366$.

${ }_{97}$ El Tribunal ha sido contundente a este respecto: «(...) In its judgement in the Chahal case the Court cautioned against reliance on diplomatic assurances against torture from a State where torture is endemic or persistent (...). In the recent case of Saadi v. Italy the Court also found that diplomatic assurances were not in themselves sufficient to ensure adequate protection against the risk of ill-treatment where reliable sources had reported practices resorted to or tolerated by the authorities which were manifestly contrary to the principles of the Convention (...). Given that the practice of torture in $U z-$ bekistan is described by reputable international experts as systematic (...), the Court is not persuaded that the assurances from the Uzbek authorities offered a reliable guarantee against the risk of ill-treatment (...)». Vid ibíd., \$127. 
esencial que, al margen de toda situación concreta, el Tribunal concede al artículo 3 como absolutamente inderogable ${ }^{98}$ y portador de uno de los valores más esenciales de una sociedad democrática ${ }^{99}$.

De entrada la jurisprudencia del Tribunal no sólo establece la necesidad de un mínimo de severidad en la conducta como para ser considerada atentatoria contra el artículo 3 del CEDH, sino que además delimita la frontera entre ambas posibles conductas lesivas. Así, los malos tratos deben alcanzar un umbral mínimo de severidad para caer dentro del ámbito del artículo $3 \mathrm{CEDH}$, siendo la valoración de dicho umbral relativa, pues dependerá de circunstancias del caso tales como la duración del trato en cuestión, sus efectos físicos y mentales, y en algunos casos también el sexo, la edad y el estado de salud de la víctima. Además, para que el trato pueda ser considerado como inhumano o degradante, el sufrimiento o la humillación infligida deben ir más allá del sufrimiento o la humillación inevitablemente asociados a toda idea de punición. Ambos casos se diferenciarían de la tortura por carecer del estigma especial que ésta conlleva, y que implicaría un trato inhumano infligido deliberadamente a fin de causar un sufrimiento serio y cruel ${ }^{100}$. Además, los tratos o penas son considerados inhumanos porque son además premeditados, aplicados durante horas y causando bien daño corporal, bien un sufrimiento físico o mental intenso. $Y$ degradantes porque provocan en quien los sufre un sentimiento de temor, angustia e inferioridad capaz de humillar a la persona ${ }^{101}$.

En este sentido el Tribunal, reconociendo que en todo caso las medidas privativas de libertad se acompañan inevitablemente de cierto grado de sufrimien-

98 Vid asunto Ireland $v$. United Kingdom, cit. supra, $\$ 163$. El TEDH ha insistido en que la prohibición se impone sea cual sea el delito que haya podido cometer o sea sospechoso de haber cometido o de cometer en el inmediato futuro el detenido (vid asunto Filip c. Roumanie (Requête n. ${ }^{\circ} 41124 / 02$, de 14 marzo 2007), $\$ 35$ ); y el asunto Ilascu \& others v. Moldova and Russia (Application n. ${ }^{\circ} 48787 / 99$, de 8 julio 2004), $\left.\$ 424\right)$.

99 Vid asunto Assenov \& others v. Bulgaria (Application n. ${ }^{\circ}$ 90/1997/874/1086, de 28 octubre 1998), $\$ 93$. En el mismo sentido vid asunto Aksoy v. Turkey, cit. supra, $\$ 62$. En otras ocasiones el Tribunal lo ha expresado en términos un poco diferentes, pero con el mismo resultado: "(...) The Court is well aware of the immense difficulties faced by States in modern times in protecting their communities from terrorist violence. However, even in theses circumstances, the Convention prohibits in absolute terms torture or inhuman or degrading treatment or punishment, irrespective of the victim's conduct (...)» (vid asunto Chahal v. The United Kingdom, cit. supra, \$79).

100 Vid asunto Saadi v. Italy, cit. supra, $\$ \$ 134-136$. En el mismo sentido vid asuntos Aydin v. Turkey, (Application n. ${ }^{\circ}$ 57/1996/676/866, de 25 de septiembre de 1997), \$82 Mamatkulov and Askarov v. Turkey, cit. supra, $\$ 70$; y asunto Chamaïev et autres c. Géorgie et Russie, cit. supra, $\$ 338$.

101 Vid asunto Labita v. Italy (Application n. ${ }^{\circ} 26772 / 95$, de 6 de abril 2000), $\$ 120$. 
to y humillación, el respeto del artículo 3 del CEDH impondría al Estado la obligación de asegurar que todo prisionero se encuentra detenido en condiciones compatibles con el respeto a la dignidad humana, que las modalidades de su detención no le someten a un estrés o una prueba de tal intensidad que exceda el nivel inevitable de sufrimiento inherente a una medida de privación de libertad y que, a la vista de las exigencias prácticas del encarcelamiento, su salud y su bienestar están asegurados adecuadamente, llamado la atención acerca de los registros corporales especialmente exhaustivos y embarazosos atentatorios contra la intimidad ${ }^{102}$. El trato será considerado degradante en la medida en que su finalidad sea humillar y rebajar al afectado y atente contra su personalidad de una forma incompatible con el artículo 3 del $\mathrm{CEDH}^{103}$.

Pero además, por su propia naturaleza, la violación del artículo 3 del CEDH por una Parte contratante conlleva que la víctima de dicha conducta se encuentre sometida a la custodia o control de dicho Estado. A este respecto es evidente la posibilidad de sufrir tratos contrarios al artículo 3 del CEDH en acciones de lucha contra el terrorismo, especialmente en fases tempranas de intervención como por ejemplo la custodia policial y, en especial, cuando las potenciales víctimas han sido aprehendidas como sospechosos o fuentes potenciales de información respecto de comportamientos de terceros.

Especialmente significativo a este respecto es el asunto Aydin v. Turkey, en el que se procede a la detención y tortura en el transcurso del interrogatorio de una mujer de 17 años a fin de obtener información sobre determinados familiares y allegados simpatizantes del PKK y que podrían tener relación con actividades terroristas, y en el que el TEDH tuvo la oportunidad de reiterar la gravedad de conductas atentatorias contra el artículo 3 del CEDH por parte de las autoridades policiales ${ }^{104}$.

Tan absoluta es la prohibición y tan reprobable esta actitud por parte de los órganos de Estado que el Tribunal no sólo ha establecido una presunción a favor de la víctima, sino que ha invertido además la carga de la prueba: cuando un individuo es puesto bajo custodia policial en perfecto estado de salud, pero se encuentra herido en el momento de su puesta en libertad o a disposición judicial, corresponde al Estado bajo cuya autoridad ha estado detenido ofrecer una explicación plausible de las causas de las heridas ${ }^{105}$.

${ }^{102}$ Vid asunto Frérot c. France (Requête n. ${ }^{\circ}$ 70204/01, de 12 septiembre 2007), $\$ 37$.

103 Vid asunto Sadak c. Turquie, cit. supra, $\$ 43$.

104 Vid asunto Aydin v. Turkey, cit. supra, $\$ \$ 82-83,85$.

105 Vid asunto Aksoy v. Turquie, cit. supra, $\$$ 61; asunto Rashid c. Bulgarie (Requête n. ${ }^{\circ}$ 47905/99, de 18 de abril de 2007), $\$ \$ 51-53$. 
Es también el caso de aquellas personas detenidas por ser consideradas como importantes fuentes de información desde el punto de vista de los servicios de inteligencia, en cuyo caso se suele añadir además el velo de la confidencialidad que, conforme a la retórica habitual de los Estados, en especial en los últimos tiempos, arropa a la seguridad nacional. No parece necesario subrayar que cuando la detención forma parte de una operación antiterrorista la vulnerabilidad del detenido se intensifica. Consiguientemente el TEDH ha exigido no sólo que las partes contratantes ordenen a sus agentes actuar respetando los límites establecidos por el artículo 3 del CEDH, sino que además establezca los mecanismos de control necesarios para comprobar dicho respeto y, en su caso, depurar responsabilidades.

El TEDH ha tenido ocasión de condenar conductas diversas como torturas, aunque es imposible ofrecer una lista exhaustiva de éstas por razones obvias, habiendo identificado en todas ellas como elemento común la severidad del sufrimiento tanto mental como físico ocasionado a la víctima. Así, el Tribunal describe el ánimo específico de infligir un daño severo que conlleva la tortura en el caso, por ejemplo, del conocido como "palestinian hanging», entendiendo que un trato tal, que implica desnudar al detenido, atarle las manos a la espalda y suspenderlo por los brazos sólo puede ser materializado deliberadamente, pues requiere no sólo cierta preparación, sino también ejercer coerción y fuerza para llevarlo a cabo ${ }^{106}$.

Y en la medida en que la tortura se administra deliberadamente y que su prohibición es absoluta, aunque se haga con un objetivo adicional —e.g. obtener información-, la prueba de dicho propósito es irrelevante y nunca podrá evitar la asunción de responsabilidades por parte de quien la inflige, ni excusar o justificar su práctica.

Si bien se puede apreciar una evolución en las técnicas de interrogatorio utilizadas durante la detención en las diferentes políticas y estrategias nacionales de lucha contra el terrorismo, desde las conocidas como "cinco técnicas», utilizadas por el Reino Unido contra los sospechosos del IRA — privación sensorial mediante la técnica de encapuchamiento, obligar a los detenidos a pasar largos periodos de tiempo en pie contra una pared con los miembros extendidos, sumisión a ruido intenso, privación de sueño o subalimentación a base de pan y agua- hacia formas más sofisticadas de tortura tales como las mock executions ${ }^{107}$, waterboarding, sumisión a temperaturas extremas, encierro en lugares muy pequeños incluso con animales dentro, en especial insectos venenosos con

106 Vid asunto Aksoy v. Turkey, cit. supra, $\$ 64$.

107 Vid, entre otros, asunto Aksoy v. Turquie, cit. supra o asunto Ilhan v. Turkey, cit. supra. 
aguijón, etc., de forma paralela ha habido igualmente una evolución en el tratamiento que el TEDH ha venido haciendo de aquellas conductas que podrían constituir tortura.

Así, desde la discutible decisión en el asunto Ireland v. The United Kingdom en el que el Tribunal consideró que las cinco técnicas especiales utilizadas durante la detención no alcanzaban el umbral de gravedad suficiente como para ser consideradas torturas ${ }^{108}$, su posición ha evolucionado, estrechando el ámbito de lo permisible y elevando el nivel de protección frente a este tipo de tratamiento. La expresión más clara de esta evolución quedó patente en la decisión en el asunto Selmouni v. France, donde el Tribunal dejó claro que ciertos actos que en el pasado podrían haber sido calificados como tratos inhumanos o degradantes por oposición a la tortura, en el futuro podrían ser calificados de diferente manera. Puesto que los estándares exigidos en la protección de los derechos humanos y las libertades fundamentales han evolucionado hacia niveles más altos, el Tribunal ha considerado inevitable elevar también la dureza en la calificación de estas conductas, en tanto que violaciones de dichos derecho y libertades ${ }^{109}$.

El Tribunal es consciente en todo momento de las dificultades que pueden plantearse en relación al interrogatorio de ciertos detenidos como sospechosos de actos terroristas quienes, bien como consecuencia de entrenamientos especiales y específicos para resistir dichos interrogatorios, o bien por miedo a sus correligionarios o por otro motivo, pueden presentar una resistencia excepcional. Incluso en estas circunstancias, y sea cual sea el delito que se sospecha el detenido puede haber cometido, incluidas las llamadas ofensas terroristas o delitos conexos con éstas, o podría cometer en el futuro, nada puede justificar el recurso a un trato contrario al artículo 3 del CEDH. Como tuvo ocasión de afirmar en el asunto Ireland $v$. The United Kingdom, la desorientación psicológica que las llamadas cinco técnicas infligían a los detenidos presentaban una entidad suficiente como para ser consideradas trato inhumano y, por lo tanto, absolutamente prohibidos por el Convenio, independientemente de la eficacia de su utilización.

Sin embargo, no por ello el Tribunal ha dejado de aceptar la posibilidad de aplicar condiciones más estrictas de detención en el caso de los sospechosos o

${ }^{108}$ Citando textualmente el razonamiento del Tribunal: «(...) On the basis of the data before it, the Court does not share this view. Admittedly, the acts complained of often occurred during interrogation and, to this extent, were aimed at extracting confessions, the naming of others and/or information, but the severity of the suffering that they were capable of causing did not attain the particular level inherent in the notion of torture as understood by the Court (...)» (vid asunto Ireland v. The United Kingdom, cit. supra, $\$ 174)$.

109 Vid asunto Selmouni v. France (Application n. ${ }^{\circ}$ 25803/94, de 28 de julio 1999), $\$ 101$. 
convictos de actos terroristas, incluido el aislamiento, pero siempre dentro de ciertos límites ${ }^{110}$ que podrían hacerlo compatible con la prohibición apuntada. En este sentido el Tribunal ha condenado como contrario al artículo 3 del $\mathrm{CEDH}$ el aislamiento sensorial y social absoluto del detenido, en la medida en que la prolongación de esta situación puede destruir la personalidad, constituyendo un trato inhumano que no puede ser justificado por razones de seguridad o de otro tipo, aunque ha considerado en cambio que la prohibición de contacto con otros presos por razones de seguridad $\mathrm{u}$ otras no constituye necesariamente trato inhumano ${ }^{111}$, a pesar de que la extensión por tiempo ilimitado de un aislamiento tan severo no es compatible con el artículo 3 del $\mathrm{CEDH}^{112}$. Así, en el asunto Öcalan v. Turkey el Tribunal aceptó un régimen de incomunicación que consideró como de relativo aislamiento social en la medida en que garantizaba al detenido, además de revisiones médicas periódicas, una celda suficientemente amplia, bien amueblada y con facilidades higiénico-sanitarias, así como un régimen de actividad diario que le permitía comunicación con los empleados de la prisión, recibir noticias del exterior mediante prensa escrita y radio, y aunque no tenía acceso a la televisión ni al teléfono, podía comunicarse con el exterior mediante cartas y recibir visitas de su abogado y familiares una vez por semana ${ }^{113}$. En tal caso será exigible un sistema de supervisión del régimen de detención.

Este planteamiento de rechazo absoluto a cualquier derogación de la prohibición de la tortura, incluso en situaciones dramáticas para los Estados como pueda ser la lucha contra el terrorismo internacional, ha sido igualmente extendida con contundencia por el TEDH a los tratos crueles, inhumanos o degradantes, aplicando para ello el mismo razonamiento, incluso en relación con la imposible la utilización a tales fines de la cláusula derogatoria admitida por el artículo 15 del $\mathrm{CEDH}^{114}$.

Finalmente en los últimos años el Tribunal ha reforzado la protección frente a la tortura o, dicho de otro modo, ha ampliado el alcance de esta prohibición absoluta, extendiendo la consideración de tortura o de trato inhumano a la situación de angustia y dolor sufrida por los familiares directos de una persona

${ }_{110}$ Vid asunto McCallum v. United Kingdom (Application n..$^{\circ}$ 9511/81, de 30 agosto 1990), $\$ \$ 30-31$.

111 Vid asunto Öcalan v. Turkey, cit. supra, $\$ 191$.

112 A pesar de que en el caso del terrorista Ramírez Sánchez, sometido a un aislamiento sensorial y social relativo durante un período de ocho años no fuese considerado contrario al artículo 3 del CEDH (vid asunto Ramírez Sánchez v. France (Application n. ${ }^{\circ}$ 59450/00, de 4 julio 2006), en especial vid $\$ 145)$.

113 Vid asunto Öcalan v. Turkey, cit. supra, $\$ 193$.

114 Vid asunto Chahal v. The United Kingdom, cit. supra, $\$ 80$. 
desaparecida a manos de las autoridades, cuando dicha desaparición se vea rodeada de una serie de circunstancias que dan al sufrimiento normal producido por estas situaciones un carácter distinto, más allá de la normal aflicción emocional. En todo caso el Tribunal ha establecido condiciones a esta extensión, subrayando entre ellas como elemento esencial para la existencia de este tipo de tortura la actitud mostrada por las autoridades ante el dolor de los familiares, pero también los lazos familiares con la víctima, las circunstancias particulares de su relación con el demandante, la posibilidad de que el familiar en cuestión que presenta la demanda haya presenciado dichos tratos, los intentos por obtener información acerca de la persona desaparecida y la respuesta de las autoridades ${ }^{115}$. Respecto de este último elemento resulta pertinente recordar el fundamento de dicha extensión: para el TEDH la esencia de esta violación no reside tanto en el hecho de la desaparición del miembro de la familia, cuanto en la reacción y actitudes mostradas por las autoridades competentes ante la denuncia de la situación, que convierte al demandante, familiar del desaparecido, en víctima de un comportamiento cruel por parte de dichas autoridades ${ }^{116}$.

\section{ALGUNAS CONCLUSIONES FINALES}

La rotundidad de las alegaciones de ciertos gobiernos ante el TEDH en algunos de los casos recientes más importantes en materia de terrorismo a favor del sacrificio de ciertos derechos fundamentales en aras de una mayor seguridad ${ }^{117}$, contrastan abiertamente con la tajante respuesta garantista del Tribunal. En este

115 Vid asunto Imakayeva v. Russia (Application n. ${ }^{\circ} 7615 / 02$, de 9 febrero 2007), $₫ 164-165$. Cabe destacar en todo caso las opiniones disidentes de algunos jueces habidas en algunos de estos casos, en la medida en que el Tribunal ha valorado como tortura esta situación en el supuesto de ascendientes de la persona muerta o desaparecida, pero no en el caso de un hermano. Vid opiniones parcialmente disidentes de los jueces Thomassen, Jungwiert and Fischbach en el asunto Çakici v. Turkey, cit. supra.

116 Vid asunto Çakici v. Turkey, cit. supra, $\$ 98$.

117 Suficientemente significativas al respecto resultan las siguientes afirmaciones del ejecutivo británico en el asunto Saadi v. Italy: "(...) in cases concerning the threat created by international terrorism, the approach followed by the Court in the Chahal case (which did not reflect a universally recognised moral imperative and was in contradiction with the intentions of the original signatories to the Convention) had to be altered and clarified. In the first place, the threat presented by the person to be deported must be a factor to be assessed in relation to the possibility and the nature of the potential illtreatment. That would make it possible to take into consideration all the particular circumstances of each case and weigh the rights secured to the applicant by Article 3 of the Convention against those secured to all other members of the Community by Article 2. Secondly, national-security considerations 
sentido, éste no sólo ha actuado como defensor del Estado de Derecho, controlando el grado de adecuación de las legislaciones y las actuaciones de los ejecutivos nacionales al $\mathrm{CEDH}$ en sus respuestas frente a las nuevas manifestaciones del terrorismo internacional, sino también recordando a los gobiernos y a los ciudadanos las responsabilidades éticas de participar en una verdadera democracia comprometida con estándares universales de protección de los derechos humanos ${ }^{118}$.

Este breve estudio de la jurisprudencia desplegada por el TEDH en relación al derecho a la libertad y a la seguridad muestra que el balance entre una lucha eficaz contra el terrorismo y el respeto de los derechos humanos, en especial el respeto del derecho a la libertad y la seguridad, no es un ejercicio mecánico ni una tarea fácil, sino que depende de cada derecho y varía respecto de cada obligación y cada situación. En aquellos casos en los que el Tribunal permite que el entorno o el contexto tengan un impacto sobre su decisión - lo que no se permite en los supuestos que pueden constituir violación del artículo 3 del $\mathrm{CEDH}$ - , éste ha tomado en consideración las circunstancias que el Estado afronta en la situación concreta, tanto políticas como tácticas. El Tribunal en definitiva no hace sino insistir, como lo han hecho importantes y decisivos pronunciamientos judiciales nacionales ${ }^{119}$, en que es posible mantener los estánda-

must influence the standard of proof required from the applicant. In other words, if the respondent State adduced evidence that there was a threat to national security, stronger evidence had to be adduced to prove that the applicant would be at risk of ill-treatment in the receiving country. In particular, the individual concerned must prove that it was "more likely than not" that he would be subjected to treatment prohibited by Article 3. That interpretation was compatible with the wording of Article 3 of the United Nations Convention against Torture, which had been based on the case-law of the Court itself, and took account of the fact that in expulsion cases it was necessary to assess a possible future risk (...) Contracting States could obtain diplomatic assurances that an applicant would not be subjected to treatment contrary to the Convention. Although, in the above-mentioned Chahal case, the Court had considered it necessary to examine whether such assurances provided sufficient protection, it was probable, as had been shown by the opinions of the majority and the minority of the Court in that case, that identical assurances could be interpreted differently (...)» (vid asunto Saadi v. Italy, cit. supra, $\$ \$ 122-123$ ).

118 Vid PLESSIS, M. de: «Terrorism and National Security: The Role of the Judiciary in a Democratic Society, E.H.R.L.R. (2007-4), pp. 327-334, en especial vid p. 332.

119 Especialmente significativa a este respecto es sin duda la sentencia de la Cámara de los Lores británica de 8 de diciembre de 2005 en el asunto $A$. $v$. Secretary of State for the Home Department, en el que el tribunal en cuestión se pronunció de forma contundente: «(...) held unanimously that the evidence of a suspect or witness which had been obtained by torture had long been regarded as inherently unreliable, unfair, offensive to ordinary standards of humanity and decency and incompatible with the principles on which courts should administer justice. It followed that such evidence might not lawfully be admitted against a party to proceedings in a United Kingdom court, irrespective of where, by whom and on whose authority the torture had been inflicted" (vid asunto A. v. Secretary of State for the Home Department [2004] UKHL 56, en 44 ILM (2005), 654, en especial \$ 27). 
res de protección y de libertad atesorados por el Estado de Derecho incluso en una sociedad amenazada por el terrorismo ${ }^{120}$.

En todas las decisiones en las que el Tribunal ha permitido dicha interferencia del entorno existe, no obstante, un elemento común: la exigencia de que el Estado en cuestión, como contrapartida a los poderes extraordinarios que pone en juego en la detención, ofrezca garantías reforzadas y mecanismos eficaces que permitan la depuración de las correspondientes responsabilidades en caso de abuso.

Puede haber diferencias acerca de si esta decisión supone una compensación adecuada o no pero, como se ha puesto de manifiesto, dado su estatuto de tribunal internacional, probablemente es la única estrategia que el TEDH ha podido adoptar al respecto hasta el momento, en la medida en que como tribunal internacional necesita de la cooperación de los Estados a la hora de ejecutar sus sentencias ${ }^{121}$.

Se ha afirmado que defender el respeto de los derechos humanos en la lucha contra el terrorismo internacional es, en primer lugar y por encima de todo, defender nuestros estándares democráticos contra aquellos que persiguen su destrucción; pero también supone, en segundo lugar, desacreditar el pretexto de los terroristas que sirve de base para abogar por el martirio y acusar a los Estados democráticos de doble rasero, lo que contribuye a la radicalización y a la generación de nuevos terroristas ${ }^{122}$.

Afirmar que una sociedad que permite la destrucción de sus garantías al arbitrio del ejecutivo no es una sociedad libre no es nuevo; lo dijo San Agustín y se ha repetido hasta la saciedad después de los ataques terroristas de 2001. Lo importante es mostrar que es posible reconducir a los gobiernos a la senda de Estado de Derecho que nunca se debió abandonar y que goza no sólo de buena salud, sino de un excelente nivel de desarrollo. En este sentido, el TEDH se ha revelado como un aliado imbatible: sistematizar su contribución, analizarla para hacerla visible y reforzar así el Estado de Derecho, sus valores y sus principios básicos, ha sido el objeto principal de este trabajo.

${ }^{120}$ Vid en este sentido ARDEN: «Human Rights and Terrorism», en Human Rights, Democracy and The Rule of Law, Liber Amicorum Luzius Wildhaber, Dike-Nomos, 2007, pp. 21-39, en especial vid p. 22.

121 Vid WARBRICK, C. cit. supra, p. 314; HEDIGAN, J.: «The European Convention on Human Rights and Counter-Terrorism», 28 FInt'lLJ (2005-2), pp. 392-431.

${ }^{122}$ MYJER, E.: «The European Convention on Human Rights, the Fight against Terrorism and the Ticking Bomb Situation» en COHEN, M. (ed.), Promoting Justice, Human Rights and Conflict Resolution through International Law/ La promotion de la justice, des droits de l'homme et du règlement des conflitc par le droit international, Liber Amicorum Lucius Caflisch, The Netherlands, 2007, pp. 379-397, en especial p. 397; WARBRICK, cit. supra, p. 301. 
Title

DETENTION, ESSENTIAL GUARANTEES AND THE RULE

OF LAW IN THE CASE-LAW OF THE EUROPEAN COURT OF HUMAN RIGHTS

\title{
Summary
}

1. INTRODUCTION. 2. POTENTIAL REASONS FOR DETENTION CONCERNING THE FIGHT AGAINST TERRORISM. 3. DETENTION CONDITIONS REGARDING TERRORIST CASES. 4. ASYLUM, REFOULEMENT AND EXPULSION CONCERNING TERRORIST CASES. 5. TERRORISM AND DETENTION WITH A VIEW TO EXTRADITION. 6. ABSOLUTE PROHIBITION OF TORTURE OR INHUMAN OR DEGRADING TREATMENT OR PUNISHMENT AS A BASIC PRINCIPLE IN ANY CASE OF DEPRIVATION OF LIBERTY. 7. SOME FINAL CONCLUSIONS.

\section{Resumen}

El derecho a la libertad y a la seguridad es probablemente, entre los derechos lesionados por la llamada "guerra contra el terrorismo», uno de los más afectados no sólo en Estados Unidos sino también en Europa. Ha sido triste descubrir las voces de los Estados miembros del Consejo de Europa defendiendo la seguridad nacional en contra de los derechos humanos y el patrimonio jurídico atesorado por el Estado de Derecho. El TEDH, arraigado en una profunda tradición democrática, ha sido capaz de resistir la tentación del momento, las presiones sociales provocadas por el terrorismo y la oposición de las Partes Contratantes del CEDH, y de contribuir de forma sustancial a este patrimonio jurídico por medio de una jurisprudencia desarrollada a lo largo de más de un centenar de casos, y en especial al derecho a la libertad y a la seguridad. El Tribunal ha sido contundente al recordar a los Estados las obligaciones éticas en materia de lucha contra el terrorismo en una sociedad verdaderamente democrática.

\begin{abstract}
Right to liberty and security probably is, among those fundamental rights shadowed by the so called "war against terrorism", one of the most affected, not only in the USA but also in Europe. It has been sad to discover CoE Member States' voices claiming in favour of national security and against human rights and the legal acquis consolidated by the Rule of Law. The European Court of Human Rights, rooted as it
\end{abstract}


is in a deep democratic tradition, has resisted against temptation, social pressure provoked by terrorism, and opposition of ECHR Contracting Parties, and has been able to contribute in a substantive way to this acquis by means of its case-law, which has been developed through more than a hundred cases, especially in the case of the right to liberty and security. The Court has been categorical when reminding Member States their ethical obligations concerning the fight against terrorism within a truly democratic society.

\section{Palabras claves}

terrorismo, Tribunal Europeo de Derechos Humanos, Convenio Europeo de Derechos Humanos, jurisprudencia, detención, derecho a la libertad y seguridad, garantías, Estado de derecho.

\section{Key words}

Terrorism, European Court of Human Rights, European Convention of Human Rights, case-law, detention, right to liberty and security, guarantees, Rule of law. 